\title{
4-Hydroxy-Trans-2-Nonenal in the Regulation of Anti-Oxidative and Pro-Inflammatory Signaling Pathways
}

\author{
Himangshu Sonowal and Kota V. Ramana \\ Department of Biochemistry and Molecular Biology, University of Texas Medical Branch, Galveston TX-77555, USA \\ Correspondence should be addressed to Kota V. Ramana; kvramana@utmb.edu
}

Received 15 April 2019; Revised 13 June 2019; Accepted 18 August 2019; Published 6 November 2019

Academic Editor: Rodrigo Franco

Copyright (c) 2019 Himangshu Sonowal and Kota V. Ramana. This is an open access article distributed under the Creative Commons Attribution License, which permits unrestricted use, distribution, and reproduction in any medium, provided the original work is properly cited.

\begin{abstract}
Recent studies indicate that 4-hydroxy-trans-2-nonenal (HNE), a major oxidative stress triggered lipid peroxidation-derived aldehyde, plays a critical role in the pathophysiology of various human pathologies including metabolic syndrome, diabetes, cardiovascular, neurological, immunological, and age-related diseases and various types of cancer. HNE is the most abundant and toxic $\alpha, \beta$-unsaturated aldehyde formed during the peroxidation of polyunsaturated fatty acids in a series of free radicalmediated reactions. The presence of an aldehyde group at $\mathrm{C} 1$, a double bond between $\mathrm{C} 2$ and $\mathrm{C} 3$ and a hydroxyl group at $\mathrm{C} 4$ makes HNE a highly reactive molecule. These strong reactive electrophilic groups favor the formation of HNE adducts with cellular macromolecules such as proteins and nucleic acids leading to the regulation of various cell signaling pathways and processes involved in cell proliferation, differentiation, and apoptosis. Many studies suggest that the cell-specific intracellular concentrations of HNE dictate the anti-oxidative and pro-inflammatory activities of this important molecule. In this review, we focused on how HNE could alter multiple anti-oxidative defense pathways and pro-inflammatory cytotoxic pathways by interacting with various cell-signaling intermediates.
\end{abstract}

\section{Oxidative Stress and Lipid Peroxidation}

Free radicals are regularly generated in aerobes because of normal respiration processes and the activity of cellular antioxidant defense machinery maintains a balance of the free radicals utilizing a variety of antioxidant enzymes in the cells. A balanced redox homeostasis is necessary for the maintenance of normal cellular processes in aerobes [1]. Under oxidative stress conditions, disruption of cellular redox homeostasis leads to an imbalance between reactive oxygen species (ROS) generation and their elimination by antioxidant enzymes. The major reasons for the redox imbalance could be the overproduction of free radical species or the inability of the cellular antioxidant defense machinery to eliminate or sequester the free radicals generated in the body. Free radicals such as superoxide anion $\left(\mathrm{O}_{2}{ }^{\cdot-}\right)$, hydroxyl radical $\left(\mathrm{OH}^{\circ}\right)$, nitric oxide $\left(\mathrm{NO}^{*}\right)$, peroxyl radical (LOO') and non-radical oxidants such as hydrogen peroxide $\left(\mathrm{H}_{2} \mathrm{O}_{2}\right)$, peroxynitrite $\left(\mathrm{ONOO}^{-}\right)$, hypochlorous acid $(\mathrm{HOCl})$, nitrous acid $\left(\mathrm{HNO}_{2}\right)$, and singlet oxygen $\left({ }^{1} \mathrm{O}_{2}\right)$, are the most commonly generated ROS in the cells and act as initiators of oxidative damage contributing to pathophysiology of multiple disease complications. Cells upon exposure to external oxidants such as xenobiotics, environmental pollutants, UV radiation, carcinogens and allergens, and internally formed oxidants in the body such as cytokines, growth factors, and chemokines could lead to altered cellular metabolic processes leading to the production of ROS. The activity of enzymes such as NADPH oxidase, xanthine oxidase, and autooxidation of glucose can generate ROS under different oxidant stimuli. In addition, mitochondrial oxidative phosphorylation that usually participates in the cellular respiration to generate energy in the cells can also contribute to the generation of free radicals (Figure 1). Apart from inducing damage to cellular macromolecules and dysregulation of cellular homeostasis, the free radicals formed during metabolic processes also act as secondary signaling intermediates and regulate various oxidative and antioxidative signaling pathways [2]. Antioxidant peptides such as glutathione (GSH) play an important role in detoxification 


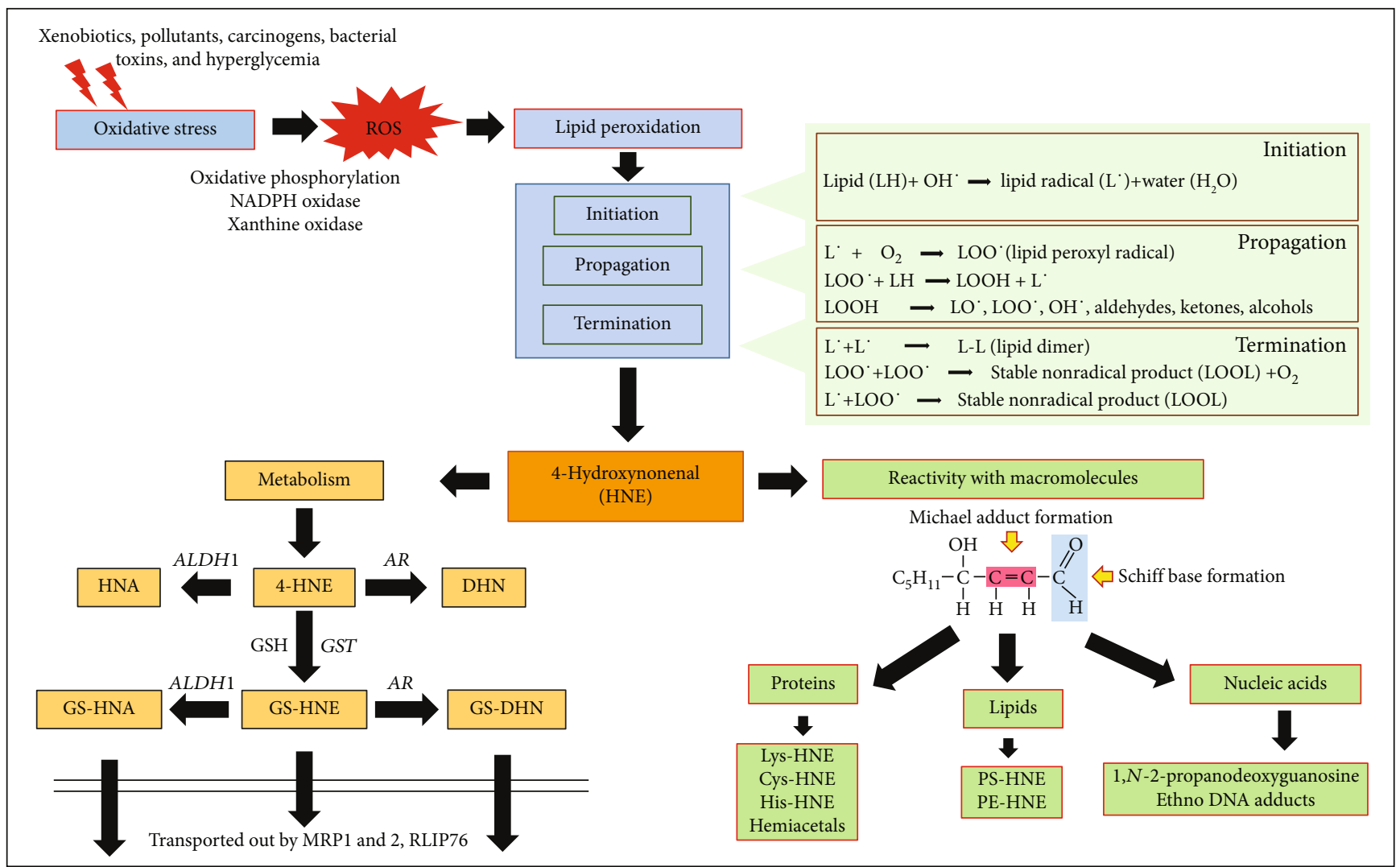

FIGURE 1: Schematic figure showing the ROS -induced formation of HNE via lipid peroxidation and its metabolism by various antioxidative enzymes.

of ROS. GSH is the most essential regulator of cellular redox homeostasis as it metabolizes or scavenges a number of free radicals or free radical- generated products in the cells. The ratio of GSH (reduced)/GSSG (oxidized) is a key indicator of cellular redox potential. Apart from GSH, enzymes such as glutathione-S-transferases (GSTs), plays a very important role in the maintenance of redox balance in cells. GSTs play a significant role in detoxification of various xenobiotics as well as endogenous toxic products generated in the cells by conjugation with GSH, facilitating further metabolism or detoxification by multiple other antioxidant detoxification and defense pathways [3]. Further, antioxidant enzyme superoxide dismutase (SOD) catalyzes the dismutation of superoxide free radical $\left(\mathrm{O}_{2}{ }^{--}\right)$, into hydrogen peroxide and oxygen. The hydrogen peroxide is further catalyzed by catalase into oxygen and water [4]. The activity of these antioxidant enzymes controls the free radical content in the body. However, during pathological complications, alterations in various antioxidant defense pathways along with increased ROS production imbalances cellular homeostasis leading to tissue damage and dysfunction.

Though ROS play an important role in regulating various physiological functions such as the elimination of pathogenic bacteria by immune cells, maintenance of vascular tone, cardiovascular functions, cell proliferation, and differentiation, a disturbance of ROS homeostasis leads to the development of various pathological complications. Several studies have shown that oxidative stress generated by ROS plays a critical role in multiple pathologies including various types of cancers, inflammatory disorders, neurodegenerative diseases, and cardiovascular complications [5, 6]. Apart from the spontaneous direct effect on DNA, RNA, amino acids, proteins and lipids, the secondary products generated by ROS -mediated reactions significantly damage various macromolecules and propagate their deleterious effects in the cells. Most importantly, even though the ROS generated in cells are short-lived, the secondary products generated by ROS are comparatively stable and further acts as important mediators of cellular signaling. The secondary ROS generated products maintain and propagate the effect of ROS long after ROS generation. These secondary toxic products could migrate to distant sites, which are far from their site of origin and can induce tissue damage and organ dysfunction in multiple sites, thus exerting multifactorial side effects. One such effect of ROS is the oxidative damage to the membrane lipids, which is termed as lipid peroxidation. Membrane phospholipids such as poly-unsaturated fatty acids (PUFA) are the major targets of lipid peroxidation induced by ROS. Lipid peroxidation-derived products such as HNE (4hydroxy-trans-2-nonenal), acrolein and malondialdehyde (MDA) are more stable; have a longer half-life than ROS themselves and have attained considerable attention in the recent past as important mediators of oxidative stressinduced pathological complications [7].

During oxidative stress, lipid peroxidation occurs via three major steps, (a) initiation, (b) propagation and (c) termination. 


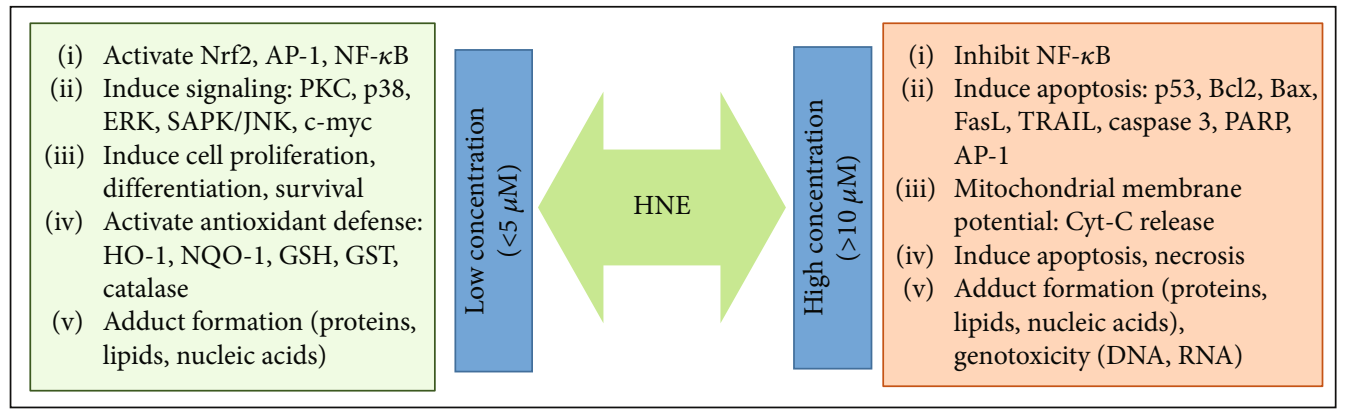

Figure 2: HNE is a pleiotropic signaling molecule: Depending on the concentration and duration of exposure, HNE induces multiple signaling pathways in cells by regulating various signaling intermediates.

In the initial initiation step, the free radicals (e.g. $\left.\mathrm{OH}^{-}\right)$attack PUFA and generates lipid radicals $\left(\mathrm{L}^{\circ}\right)$. The removal of hydrogen atoms from the lipids leads to the reduction of ROS into water and generation of lipid radicals. During propagation step, the unstable lipid radicals react with oxygen leading to the generation of lipid peroxyl radicals (LOO') and additional lipid radicals $\left(\mathrm{L}^{\circ}\right)$, which further reacts in a chain reaction and new lipid radicals and lipid peroxides are generated. The presence of metal ions such as iron $\left(\mathrm{Fe}^{2+}\right)$ and copper $\left(\mathrm{Cu}^{2+}\right)$ is shown to accelerate the propagation reaction. In the final termination step, hydroperoxides are generated by the reaction of peroxyl radicals with vitamin $\mathrm{E}$ ( $\alpha$-tocopherol). The lipid peroxides and lipid radicals react with each other to generate more stable non-radical products during the termination of the lipid peroxidation process (Figure 1). The $\beta$-oxidation of lipid peroxides leads to the generation of various toxic lipid aldehydes such as alkanals, alkenals, hydroxyalkenals, and alkadienes $[8,9]$. The formation of lipid aldehydes such as MDA and HNE is often considered as the most common toxic end products of lipid peroxidation and generally used as indicators of oxidative damage in the cells and tissues. Further, the $\alpha, \beta$-unsaturated hydroxyalkenal, HNE has been shown to be the most abundant and toxic lipid peroxidation end product generated during lipid peroxidation $[8,9]$. HNE with its highly reactive electrophilic groups can interact with cellular proteins, GSH, nucleic acids and can cause cytotoxicity or genotoxicity (Figure 1). Recent studies have postulated that HNE is a biomarker of oxidative stress-induced pathological complications and correlated its damaging effects to various human diseases such as cancer, neurodegenerative, inflammatory and autoimmune diseases, various metabolic diseases, and mitochondrial dysfunction $[8,10-15]$. Besides its reactivity with macromolecules, HNE can also alter the membrane potential, electron transport and ion imbalance in the cells leading to neurological disorders [16, 17]. Further, HNE also plays an important role in cell survival and death by signaling through different pathways mediated by caspase $3, \mathrm{Bax}, \mathrm{Bcl} 2$, death receptors, multiple kinases and transcription factors such as Nrf2, AP-1 and NF- $\kappa$ B (Figure 2) [18-21]. The effect of HNE on the cellular macromolecules is dependent on the type of tissue and concentration of HNE, with specificities for proteins containing cysteine, histidine and lysine residues $[8,9,22]$. The detoxification and metabolism of HNE is also differential in different tissues [23]. In the succeeding section, we have discussed the reactivity of HNE with different macromolecules and its metabolism.

\section{Reactivity and Metabolism of HNE}

$\mathrm{HNE}$ has three functional groups 1) carbonyl group on $\mathrm{C} 1$ $(\mathrm{C}=\mathrm{O}), 2)$ a double bond between $\mathrm{C} 2$ and $\mathrm{C} 3(\mathrm{C}=\mathrm{C})$ and 3$)$ hydroxyl group on $\mathrm{C} 4$ (which facilitates $\mathrm{C}=\mathrm{C}$ polarization and cyclization reactions), which makes $\mathrm{HNE}$ a highly reactive aldehyde product of lipid peroxidation process (Figure 1). HNE can react with different macromolecules such as proteins, phospholipids, nucleic acids, and glutathione (GSH). Membrane-bound entities and proteins containing an abundance of cysteine, lysine and histidine residues and phospholipids such as phosphatidyl-ethanolamine are preferred targets for adduct formation by HNE. Electrophilic sites of HNE leads to Schiff base formation between an amino group and the carbonyl group at $\mathrm{C} 1$ and Michael addition of thiol or amino compounds at C3 $[9,24,25]$. The reactivity of HNE towards amino acids has been shown to be in the order of cysteine $>$ histidine $>$ lysine [26-28]. First, the amino acids undergo Michael addition at the $\mathrm{C}=\mathrm{C}$ double bond of HNE. Michael addition to the $\mathrm{C}=\mathrm{C}$ bond confers rotational freedom at the $\mathrm{C} 2-\mathrm{C} 3$ bond, which facilitates secondary reactions of primary amines with the carbonyl group of HNE to form Schiff bases [29]. Although cysteine is the most preferred amino acid for reactivity with HNE, HNE-histidine adducts have been shown to be more stable as compared to cysteineand lysine-HNE adducts $[28,30]$. Further, HNE-induced covalent modification of nucleophilic residues of amino acids regulate protein activation/inactivation, which could alter cellular signaling pathways. Specifically, important cellular signaling pathways controlling apoptosis, cell cycle, oxidative and nitrosative stress-associated pathways are reported to be significantly affected by HNE leading to cellular toxicities [31-33]. HNE also inhibits the proteasomes such as $20 \mathrm{~S}$ proteasome and hence impairs the cellular proteasomal degradation of damaged or modified protein subunits generated subsequent to oxidative stress [34]. Chaperone activities specifically mediated by HSP 72 and HSP 90 have been shown to be modified by HNE adduct formation [35, 36]. HSP 90 function has been reported to be modified by the modification of Cys-572 residue by HNE, which has important pathological implications in alcoholic liver diseases 
(ALD) $[36,37]$. HNE can directly interact with guanosine bases in DNA to form 1,N-2-propano-deoxyguanosine with an ability to form $1.2 \pm 0.5$ adducts $/ 10^{7}$ nucleotides [38]. Etheno-DNA ( $\varepsilon$-DNA) adducts have been shown to be generated by the reaction of HNE with nucleotides in DNA that could lead to mutational changes in DNA, increasing the susceptibility to cancerous transformation in cells [39]. Formation of HNE-DNA adducts indicate the genotoxic and mutagenic effects induced by lipid peroxidation [40]. HNEDNA adduct formation hampers DNA repair mechanism in the cells. Studies have shown that HNE inhibits nucleotide excision repair in DNA damage-induced either by UV radiation or carcinogens such as benzo[a]pyrene diol epoxide (BDPE); a major environmental pollutant and component of cigarette smoke $[41,42]$. Thus, these studies provide evidence that HNE is a multifactorial effector of signaling and cellular functions in the body.

HNE is short-lived in the cells with a half-life of less than $2 \mathrm{~min}$ and is immediately conjugated with other macromolecules or metabolized by various antioxidant enzymes [43]. Based on cellular antioxidant defense capacity and cell types, multiple studies have demonstrated varying concentrations and half-life of HNE in vitro and in vivo [44]. Major cellular metabolic pathways which play an important role in the detoxification of HNE are: (a) alcohol dehydrogenase (ADH) or aldose reductase (AR, AKR1B1), which reduces $\mathrm{HNE}$ to 1,4-dihydroxy-2-nonene (DHN), (b) aldehyde dehydrogenase (ALDH), which oxidizes HNE to 4-hydroxy-2-nonanoic acid (HNA) and (c) glutathione-S-transferases (GSTs), which catalyze the conjugation of HNE to GSH forming GS-HNE, which is then transported out of the cell in an ATP-dependent manner by various drug transporters such as MRP1, MRP2, and RLIP76 (Figure 1) [8, 45-47]. HNE has the ability to induce modifications in enzymes involved in cellular detoxification such as GSTs [48], glutathione reductase (GR) [49], either by Michael adduct formation or by covalent modifications of amino acid residues in the proteins. Interestingly, the cellular GSH levels control the concentration of HNE in cells and on the other hand, HNE has been shown to regulate the expression of enzymes responsible for GSH synthesis. Exposure of cells to HNE has been shown to increase $\gamma$-glutamate cysteine ligase (GCL) activity. GCL catalyzes the rate-limiting step in GSH biosynthesis and hence is important for the maintenance of cellular GSH levels. Further, HNE has also been shown to induce the transcriptional activation of $\gamma$-glutamyl cysteine synthase, thus contributing to enhanced GSH biosynthesis [50]. HNE can conjugate with GSH spontaneously or by the conjugation reactions catalyzed by the specific GST isozymes $[51,52]$. GSTA4-4 and GST5.8 have been shown to specifically participate in the GSH-conjugation with $\mathrm{HNE}[53,54]$. Studies have shown that overexpression of HNE metabolizing GST (mGSTA4-4, hGSTA4-4, or hGST5.8) confers protection to cells against oxidative injury [55]. Exposure of hepatoma cells to exogenous HNE leads to the formation of major metabolites of HNE: glutathione-HNE (GS-HNE) indicating the importance of HNE-GSH conjugation as a major metabolic route for its detoxification [47]. Apart from GST, studies have also demonstrated that aldose reductase (AR; AKR1B1) further metabolizes GS-HNE to GS-DHN and aldehyde dehy- drogenase $(\mathrm{ALDH})$ isozymes metabolize GS-HNE to GSHNA $[54,56]$. Several studies have demonstrated that aldoketo reductases are an important class of enzymes upregulated by oxidative stress or exposure to HNE [57]. Up-regulation of AR has been shown to play an important role in HNE detoxification in HepG2 cells. Burczynski et al., have demonstrated that HNE generated in the cells induces its own metabolism and detoxification by up-regulating the aldo-keto reductase isozyme AKR1C1 [58]. Both HNE and its GSH metabolite, GS-HNE, have been shown to be reduced by AR to 1,4dihydroxy-2-nonene (DHN) and GS-DHN, respectively [59-62]. Further, AR reduces GSH conjugates of aldehydes (e.g. GS-HNE and GS-acrolein) more effectively as compared to their parent aldehydes (e.g. HNE and acrolein) indicating that AR has a specific binding site for glutathionylated aldehydes $[63,64]$. Indeed, Singh et al., have crystallized AR bound GS-analogue and found that AR has specific GSaldehyde binding domain [65]. These studies demonstrate that catalytic activity mediated by $\mathrm{AR}$ is a major step in the detoxification of lipid peroxidation-derived aldehydes such as HNE and their glutathione conjugates. Indeed multiple studies modulating AR activity have shown to exert therapeutic effects in various oxidative stress-induced inflammatory pathologies including cancer [56, 66-68].

HNE-mediated regulation of signaling pathways is pleiotropic and the signaling pathways activated or inhibited by HNE depends on the concentration of HNE and the type of cells used in the study. In cell culture studies, HNE concentration greater than $10 \mu \mathrm{M}$ has been reported to induce apoptosis whereas sub-lethal dose $\leq 5 \mu \mathrm{M}$ induces cell proliferation. Concentration-dependent activation of various pro-inflammatory and anti-oxidative pathways by $\mathrm{HNE}$ is shown to regulate multiple kinases and transcription factors important for disease pathology (Figure 2). In certain pathologies, a very high concentration of $\mathrm{HNE}$ has been observed. Elevated plasma levels of HNE $(\sim 100 \mu \mathrm{M})$ have been reported in children with systemic lupus erythematosus [69] and in the liver tissues of mouse models of experimental alcoholic liver disease [70, 71]. However, it is still unclear how the cells cope with such high levels of HNE in vivo and the deleterious effect exerted by such high concentrations of HNE in various human diseases. With the increasing evidence of the importance of ROS and lipid peroxidation-derived aldehydes in different human pathologies, and advancement in analytical techniques to detect and identify the specific role of free radical intermediates in various diseases [72], studies on the roles of lipid peroxidationderived aldehydes in modulating cellular signaling pathways has attained a considerable attention in the recent years. In the following section, we have briefed some of the important findings on the role of HNE in mediating anti - and proinflammatory signaling pathways.

\section{Regulation of Anti-oxidative Pathways by HNE}

NFE2-related nuclear factor 2 (Nrf2) is a master transcription factor regulating the expression of genes involved in the anti-oxidative and anti-inflammatory pathways [73]. 


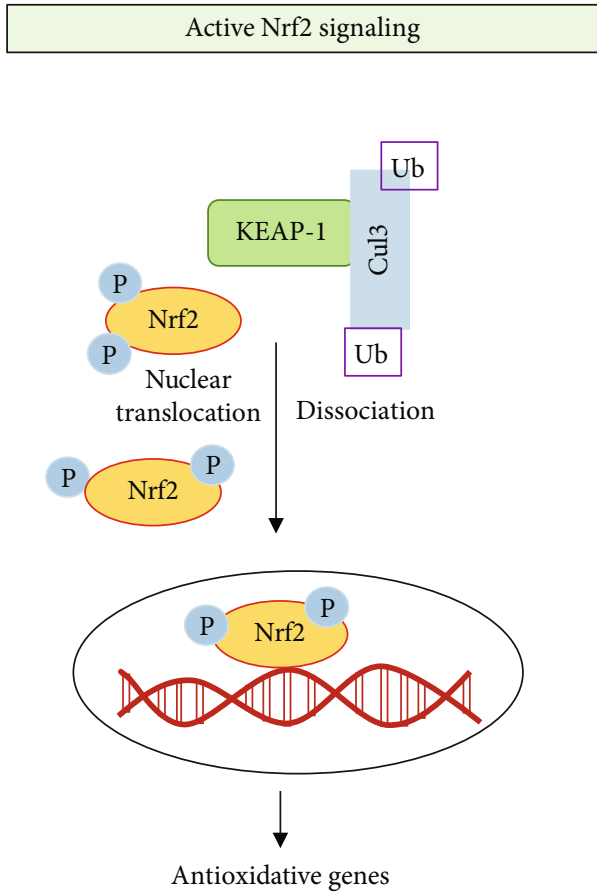

(a)

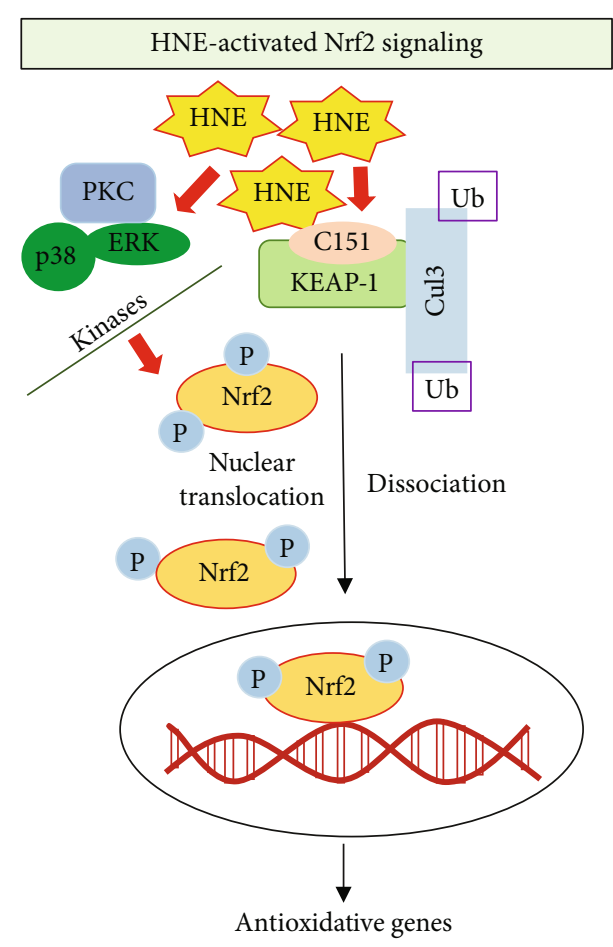

(b)

FIGURE 3: Role of HNE on Nrf2-mediated anti-oxidative signaling: Nrf2 is a master regulator of various anti-oxidative and anti-inflammatory pathways in the cells. Under basal conditions, Nrf2 is bound to KEAP-1 and remains inactive. KEAP-1 is an adaptor protein and association of KEAP-1 with Cul3, promotes proteasomal degradation of the Nrf2-KEAP1 complex. However, when activated by an external stimulus, (a) phosphorylation and dissociation of Nrf2 occurs from the Nrf2-Keap1 complex leading to nuclear translocation of Nrf2 and transcription of target genes. (b) HNE could promote Nrf2 activation either by modifying the C151 residues in KEAP-1 or by promoting Nrf2 phosphorylation directly. Apart from directly affecting Nrf2 and KEAP-1, various upstream kinases such as p38MAPK, PKC and ERK can also be modulated by HNE, which further initiates the activation of Nrf2.

Various exogenous stimuli such as xenobiotics, flavonoids, and antioxidants activate Nrf2 nuclear translocation, which then binds to its consensus antioxidant response elements (ARE) and induces the transcription of anti-oxidative genes. Under the basal conditions, Nrf2 is sequestered in the cytoplasm by its association with KEAP1, which keeps the complex inactive. The Nrf2-KEAP1 complex is ubiquitylated and subsequently, the association of Nrf2-KEAP1 complex with $\mathrm{Cul} 3$ induces proteasomal degradation. However, under conditions of oxidative stress or antioxidant stimuli, phosphorylation of Nrf2 triggers its dissociation from KEAP1. The active Nrf2 is then translocated to the nucleus and binds to its consensus ARE to activate respective antioxidant defense genes [74, 75]. (Figure 3).

Activation of the KEAP1-Nrf2 signaling pathway has been shown to be a major approach for HNE-induced cellular antioxidant defense. HNE is electrophilic in nature and hence activates the EpRE/ARE response elements. The highly reactive cysteine residues in KEAP1 makes it a preferred target for electrophilic attack by HNE [76]. Specifically, HNE has been shown to modify the cysteine amino acid residue at $\mathrm{C} 151$ in the $\mathrm{BTB}$ domain of KEAP1 leading to the dissociation of KEAP1 from the Nrf2-KEAP1 complex [76]. Three distinct cysteine amino acid-based sensors in KEAP1 have been reported to be recognized by carbonyl groups of HNE [77]. Apart from directly modulating
KEAP1-Nrf2 interaction, HNE can also modulate various upstream protein kinases that are required for the phosphorylation Nrf2. Among these, PKC [78], PI3K [79] p38-MAPK, and ERK [80] have been shown to be important cellular protein kinases whose activities are specifically regulated by HNE. Although the precise mechanism of how these kinases modulate HNE-induced Nrf2 activation is not known, it is hypothesized that the adduct formation of protein kinases with HNE could alter the physiological functions of these protein kinases and favor phosphorylation of $\mathrm{Nrf} 2$ at specific sites (Figure 3).

Activation of Nrf2 either directly or indirectly acts as an important transcriptional regulator of various Phase -II detoxifying enzymes conferring protection to cells against oxidative damage [81]. Some important Phase- II detoxification enzymes activated by HNE include aldo-keto reductases (AKRs), $\gamma$-glutamylcysteine ligase (GCL), glutathione peroxidase (GPX), glutathione-S-transferase (GST), NADPH quinone oxidoreductase 1 (NQO1), heme oxygenase 1 (HO-1), thioredoxin (Trx), thioredoxin reductase (TrxR), and drug transporter proteins such as MRPs, Pgp1 and RLIP76. All the Phase-II detoxification enzymes have been shown to have specific ARE consensus sequences for Nrf2 binding in response to oxidative stress [82]. It is important that under oxidative stress, the major cellular detoxification pathways are activated in a concerted mechanism as a 
defense response to maintain the cellular redox balance homeostasis to confer protection against oxidative injury.

Several studies have demonstrated that the activation of Nrf2 plays an important role in the detoxification of xenobiotics, including lipid peroxidation products such as $\mathrm{HNE}$ $[83,84]$. Miller et al., have shown that the intraperitoneal injection of Nrf2-ARE activators such as sulforaphane or carnosic acid protects cerebral cortical mitochondria from HNE-induced toxicity. Further, treatment with sulforaphane or carnosic acid up-regulated the mRNA levels of antioxidant enzymes such as HO-1 and prevented HNE-induced disruption of mitochondrial respiration [85]. HNE has also been shown to induce the expression of antioxidant enzymes AKR1C1, GSTA4, and HO-1 in HeLa cells, which play an important role in the protection against oxidative stressinduced toxicity [86]. Using siRNA-mediated silencing of Nrf2, this study has provided strong evidence that Nrf2 plays an important role in exerting protection against HNEinduced toxicity in HeLa cells [86]. Exposure to low concentrations of $\mathrm{HNE}(<5 \mu \mathrm{M})$ is likely to induce an elevated antioxidant response, which prepares the cells to cope with oxidative insults. Incubation of macrophages and vascular smooth muscle cells with HNE has been shown to activate Nrf2 and protect cells from oxidative injury during vascular complications. Abundant formation of lipid peroxidation products such as HNE has been reported in atherosclerotic plaques and hence identifying the signaling pathways regulated by HNE in vascular cells is of immense importance in atherosclerosis [87]. Gargiulo et al., have shown that the exposure of monocytes to HNE induces various inflammatory cytokines such as IL- $1 \beta$, IL- 8 , and TNF- $\alpha$ which regulate atherosclerotic plaque stability $[88,89]$. Incubation of HNE with murine peritoneal macrophages isolated from Nrf2 knockout mouse models did not show increased expression of HO-1, Prx1, and A170 antioxidant proteins, indicating the significance of Nrf2 in HNE-induced protective effects [88]. HNE-induced upregulation of CD36, a major scavenger receptor, has been shown to exert protective functions during atherosclerosis and oxLDL-induced oxidative damage in an Nrf2 dependent manner [90]. Studies have demonstrated that multiple antioxidant response elements and oxLDL uptake receptors are HNE targets, which play an important role in atherosclerosis progression, the anti-oxidant response in endothelial and vascular cells and atheroprotective functions [91, 92]. In $661 \mathrm{~W}$ retinal ganglion cells, apart from upregulating the nuclear translocation and Nrf2-ARE transcription activity, treatment with $5 \mu \mathrm{M}$ HNE induced the expression of antioxidant genes such as Trx, TrxR, and HO-1, exerting protective functions. Similarly, the upregulation of antioxidant genes by $\mathrm{HNE}$ conferred protection against $\mathrm{H}_{2} \mathrm{O}_{2}$-induced apoptosis in $661 \mathrm{~W}$ cells [93]. This study also demonstrated that siRNA-mediated silencing of $\mathrm{Nrf} 2$ failed to confer protection induced by $\mathrm{HNE}$ against $\mathrm{H}_{2} \mathrm{O}_{2}$-induced cell damage [93]. However, the signaling mechanisms activated by HNE are elusive. As we have already discussed in the preceding section that the concentration of HNE used in a study could act as an important factor to properly decipher the signaling mechanisms activated or inhibited by HNE (Figure 2). In studies using primary cul- tures of human optic nerve head astrocytes, it is observed that HNE concentrations greater than $50 \mu \mathrm{M}$ induce apoptosis and significantly decrease the cellular GSH levels [94]. Treatment with a lesser concentration of $\operatorname{HNE}(<25 \mu \mathrm{M})$ also leads to a significant decrease in cellular GSH levels after $1 \mathrm{~h}$ and $3 \mathrm{~h}$ of treatment. However, when the cells were allowed to recover for $24 \mathrm{~h}$ without HNE after $1 \mathrm{~h}$ or $3 \mathrm{~h}$ treatment with $25 \mu \mathrm{M}$ HNE, significant restoration of GSH levels have been observed [94]. In this study, real-time PCR gene expression analysis of mRNA also showed a significant increase in the levels of AKR1C1, GSTA4 and GCLC mRNA along-with increase in transcription factor Nrf2 and c-Fos. Thus, the concentration and time of exposure to HNE are important in mediating HNE-induced antioxidant responses, which prepares the cells for protection against oxidantinduced damage [94]. It is already clear that strategies such as using natural or synthesized antioxidants to activate or augment Nrf2 mediated cellular antioxidant defense pathways exert protective functions against oxidative stress injury by multiple oxidants including lipid peroxidation products $[86,95]$. Thus, HNE-mediated activation of Nrf2 may be an important step in regulating the HNE-induced antioxidant response in cells and tissues.

Studies to decipher the molecular mechanisms of HNEmediated antioxidant defense response has provided evidence that apart from Nrf2-mediated regulation of antioxidant response, HNE has the ability to directly regulate the transcriptional activity of other antioxidant enzymes responsible for GSH biosynthesis. HNE regulates GSH levels by regulating the rate-limiting step of GSH biosynthesis by modifying Cys553 of the catalytic subunit ( 73 kDa GCLC) and Cys35 of the modulatory subunit ( $31 \mathrm{kDa}, \mathrm{GCLM})$ of glutamate-cysteine ligase (GCL) [96]. GCL is a heterodimeric holoenzyme complex consisting of a $73 \mathrm{kDa}$ catalytic subunit (GCLC) and a 31-kDa modifier subunit, which catalyzes the first and rate-limiting step of GSH biosynthesis [97]. Further, HNE induces the promoter activity of $\gamma$-glutamyl transpeptidase (GGT) by interacting with an electrophile response element (EpRe) in the proximal region of GGT promoter region 5 (GP5). GGT plays an important role in glutathione homeostasis and metabolism of GSH and hence increasing the transcriptional activity of GGT confers protection against oxidative injury. Moreover, HNE has been shown to be involved in Nrf2 binding to the GP5 EpRE complex [98]. Apart from directly inducing GGT promoter activity, HNE could also activate various upstream MAPK kinases such as ERK and p38-MAPK, which are involved in the activation of GGT. The transcriptional regulation of EpRE by p38MAPK and ERK has been shown to induce GGT mRNA transcription, which regulates antioxidant response and cellular homeostasis [99]. MAPKs could act as important components in the regulation of Nrf2 activity induced by HNE as they have been reported to directly induce phosphorylation of Nrf2 leading to its activation [80]. Further, the transcription factor AP1 has been shown to be involved in the HNE-induced increase in the glutamate cysteine ligase (GCL) expression by regulating antioxidant response [100, 101]. These studies have provided evidence that multiple signaling pathways co-operate to induce antioxidant defense 


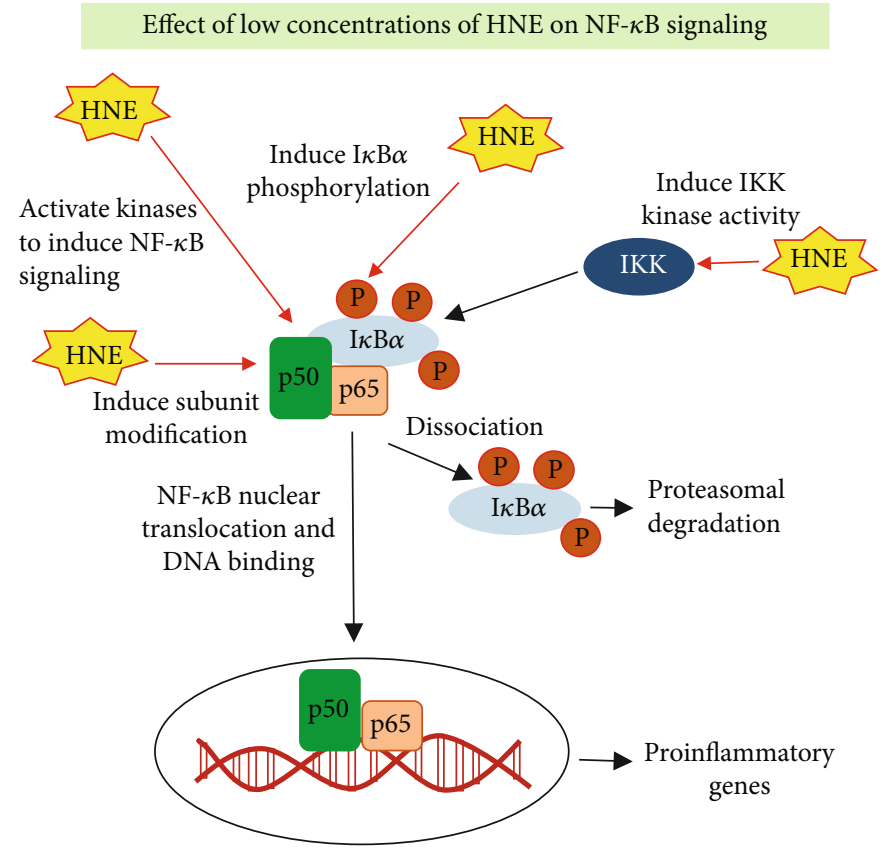

(a)
Effect of high concentrations of HNE on NF- $\kappa$ B signaling

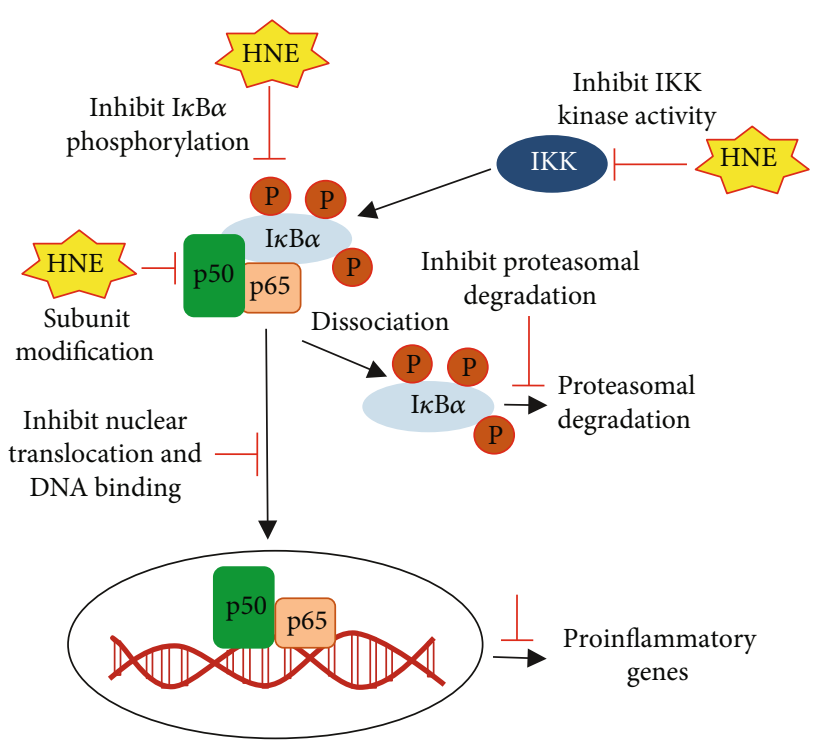

(b)

FIgURE 4: Role of HNE on NF- $\kappa$ B-mediated pro-inflammatory signaling: During oxidative stress conditions ROS activate a series of protein kinases such as IKK which phosphorylates $\mathrm{IkB} \alpha$ leading to dissociation of the inactive complex of NF- $\kappa \mathrm{B}-\mathrm{I} \kappa \mathrm{B} \alpha$. The active NF- $\kappa \mathrm{B}$ is translocated to the nucleus and binds to its consensus sequences to induce the transcription of target genes. HNE exerts pleiotropic effects on NF- $\kappa$ B; (a) the low concentrations of $\operatorname{HNE}(<5 \mu \mathrm{M})$ could activate NF- $\kappa$ B whereas (b) high concentrations $(>5 \mu \mathrm{M})$ of $\mathrm{HNE}$ could inhibit NF- $\kappa$ B. HNE could modulate NF- $\kappa$ B activity by interacting with upstream protein kinases and can directly modify NF- $\kappa$ B subunits.

response induced by HNE. Low concentrations of HNE has been shown to induce the expression of cytoprotective genes such as thioredoxin reductase 1 (TrxR1) in a Nrf2/ERK/Aktdependent pathway in PC12 cells [102]. Further, the expression of TrxR1 has been shown to induce an adaptive response and enhances cellular tolerance to oxidative insult. The HNEinduced ERK and AKT signaling pathways may directly or indirectly affect Nrf2 expression in PC12 cells [102]. HNEmediated activation of ERK also plays an important role in the regulation of HO-1 expression induced by HNE. In rat pulmonary epithelial cells, $\mathrm{HO}-1$ expression is reported to be translationally regulated by HNE-mediated phosphorylation of ERK [103].

ROS are important for HNE production; ROS-induced lipid peroxidation is a major source of HNE generation in cells $[7,9]$. Furthermore, studies have provided evidence that HNE itself could induce ROS generation in cells; the HNEinduced ROS further propagates the effects of HNEmediated antioxidant defense mechanisms in cells [104]. On the other hand, a few studies showed that ROS could play a bystander effect on HNE-induced cell signaling. Studies on PC12 cell lines provide evidence that HNEinduced cell damage was a result of HNE-induced modification of cellular GSH or modification in cysteine and histidine residues in proteins rather than the direct effect of ROS alone. HNE-induced apoptosis, intercellular $\mathrm{Ca}^{+2}$ accumulation, caspase activation and cellular quiescence were not ameliorated by scavenging the ROS generated in cells [105]. Thus, protein modifications, rather than ROS generation in HNE exposed cells seem to be a major regulator of HNE- mediated cell signaling [105]. Several other pathways such as the unfolded protein response- (UPR) and ER stressassociated signaling pathways have been shown to be affected by HNE [105]. In the same study, they have demonstrated that HNE induces ER stress by regulating ATF4 expression which regulates the unfolded protein response (UPR). A significant increase in UPR target genes such as GRP78 and CHOP has been observed in PC12 cells treated with HNE [105]. Thus, HNE by interacting with various protein kinases such as MAPK and AKT, transcription factors and AREs regulates the Nrf2-mediated antioxidant pathways in the cells. Furthermore, exposure of cells to low concentrations of HNE prepares the cells to withstand further oxidative injury, whereas a high concentration activates the apoptotic pathways leading to cellular toxicity.

\section{Regulation of Pro-Inflammatory Pathways by HNE}

Besides the regulation of Nrf2-mediated anti-oxidant pathways, HNE has been shown to regulate various proinflammatory pathways mediated by NF- $\kappa \mathrm{B}$ and AP1. The activation of these pathways leads to the expression of multiple cytokines, chemokines and growth factors responsible for inflammatory response and various disease pathologies. NF$\kappa \mathrm{B}$; a major redox-sensitive transcription factor activated during oxidative stress conditions, is a key regulator of cell viability and death [106]. Various studies have provided evidence of the myriad and elusive role of HNE as a critical regulator of NF- $\kappa \mathrm{B}$-mediated inflammatory signaling 
pathways in cells. NF- $\kappa \mathrm{B}$ is a heterodimeric transcription factor with five subunits consisting of p50, p52, p65, c-Rel, and RelB. In the inactive state, the NF- $\kappa$ B complex is localized in the cytoplasm due to its association with $\mathrm{I} \kappa \mathrm{B} \alpha$. Upon stimulation by exogenous stimuli, NF- $\kappa \mathrm{B}$ is phosphorylated and translocated to the nucleus where it binds to its consensus DNA sequence element and induces transcription of target genes. The $\mathrm{I} \kappa \mathrm{B}$ kinases (IKK) play an important role in the activation of NF- $\kappa \mathrm{B}$ by inducing phosphorylation on serine residues of $\mathrm{I} \kappa \mathrm{B} \alpha$, which leads to dissociation of $\mathrm{I} \kappa \mathrm{B} \alpha$ from $\mathrm{NF}-\kappa \mathrm{B}$, leading to NF- $\kappa \mathrm{B}$ activation and nuclear translocation. After dissociation, $\mathrm{I} \kappa \mathrm{B} \alpha$ is polyubiquitinylated and degraded by the proteasome [106].

HNE can induce either activation or inhibition of NF- $\kappa \mathrm{B}$ depending on the cell type and concentration (Figure 4). Although the mechanisms are not clearly understood, it has been shown in many studies that exposure to a high concentration of HNE inhibits the activation of NF- $\kappa \mathrm{B}$ [107]. In fact, oxidative stress-induced $\mathrm{HNE}$ and NF- $\kappa \mathrm{B}$ activation are positively correlated with the increased inflammatory response in many studies [108-113].

It has been demonstrated in THP1 cells that HNE prevents phosphorylation of $\mathrm{I} \kappa \mathrm{B} \alpha$, which is necessary for NF- $\kappa$ B activation. Specifically, pre-treatment of THP1 cells with $25 \mu \mathrm{M}$ HNE resulted in the reduction of LPS-induced phosphorylation in Ser-32 of $\mathrm{I} \kappa \mathrm{B} \alpha$, thus preventing the activation of NF- $\kappa$ B by HNE [114]. Besides LPS, HNE also inhibits phosphorylation of $\mathrm{I} \kappa \mathrm{B} \alpha$ induced by IL- $1 \beta$ and Phorbol 12-myristate 13-acetate (PMA) in monocytes [114]. Studies have further demonstrated that HNE could directly regulate the activity of IKK Kinase by forming covalent adducts with the IKK complex. IKK-induced phosphorylation $\mathrm{I} \kappa \mathrm{B} \alpha$ is necessary for $\mathrm{NF}-\kappa \mathrm{B}$ activation [115]. Studies using H1299 and Jurkat T-cells have shown that pretreatment with HNE blocks TPA- or ionomycin-induced activation of NF- $\kappa \mathrm{B}$ [115]. HNE could also regulate NF- $\kappa \mathrm{B}$ by directly forming adducts with important signaling intermediates. In a model of long-term hepatic injury following alcohol exposure to rodents, $\mathrm{HNE}-\mathrm{I} \kappa \mathrm{B} \alpha$ adduct formation has been demonstrated to inhibit NF- $\kappa \mathrm{B}$, which is independent of IKK phosphorylation [116]. Inhibition of NF- $\kappa$ B by HNE exerts anti-inflammatory effects. HNE-induced inhibition of NF- $\kappa$ B prevents LPS-induced production of IL- 6 in rat kupffer cells [117]. HNE-IKK adduct formation and suppression of $\mathrm{I} \kappa \mathrm{B} \alpha$ phosphorylation could lead to the inhibition of NF- $\kappa \mathrm{B}$. HNE has been shown to prevent IL- $1 \beta$ induced nuclear translocation of $\mathrm{p} 65$ and NF- $\kappa \mathrm{B}-\mathrm{DNA}$ binding [118]. Similarly, in rat cortical neuronal cells, exposure to HNE prevented the NF- $\kappa$ B-DNA binding activity [119].

On the other hand, many studies have provided substantial evidence that HNE activates NF- $\kappa$ B (Figure 4). Exposure of cells to low concentrations of $\operatorname{HNE}(1 \mu \mathrm{M})$ induces the activation of NF- $\kappa \mathrm{B}$ in vascular smooth muscle cells [120]. The same concentration of HNE has been shown to induce phosphorylation and DNA-binding of NF- $\kappa$ B [120]. Similarly, another study demonstrates that exposure of vascular smooth muscle cells to HNE increases ROS production and activation of NF- $\kappa \mathrm{B} / \mathrm{AKT}$ signaling pathway leading to cell proliferation [121]. 5-Lipoxygenase (5-LOX) plays an important role in inflammation and atherosclerotic plaque formation. HNE has been shown to induce 5-LOX mRNA expression in murine macrophages by signaling through NF- $\kappa$ B, p38MAPK and ERK [122]. Similarly, exposure of murine macrophages to LPS increased ROS production and subsequently increased lipid peroxidation products [123]. Results from this study also demonstrate that HNE is an important mediator of LPS-induced inflammation by increasing the release of inflammatory cytokines such as TNF- $\alpha$, IL- $1 \beta$, IL-6, and MCP-1 [123]. HNE-mediated increase in the NF- $\kappa \mathrm{B}$ activity has been shown to be involved in inflammatory signaling in rheumatoid arthritis. Treatment of synovial cells with $5 \mu \mathrm{M}$ HNE resulted in a timedependent increase in IL-1 $\beta$, IL-6, and TNF $\alpha$ [124]. Exposure to a higher concentration of $\operatorname{HNE}(50 \mu \mathrm{M})$, led to a transient increase in IL- $1 \beta$, IL-6, and TNF- $\alpha$, with the maximum increase observed after $1 \mathrm{~h}$. However, the levels of inflammatory cytokines gradually decreased after 6 and $12 \mathrm{~h}$. Increase in Cox 2 expression, an important inflammatory mediator was also observed in the same study [124]. Further, HNE has been reported to induce endothelial dysfunction, by increasing the production of NF- $\kappa \mathrm{B}$-mediated expression of IL-8, ICAM, and impairment of endothelial barrier function [125].

Although the literature provides conflicting data on the role of $\mathrm{HNE}$ in inhibiting or activating $\mathrm{NF}-\kappa \mathrm{B}$ based on its concentration, it is clear that exposure of cells to $\mathrm{HNE}$ induces a state of oxidative stress imbalance in the cells. Exposure to HNE leads to depletion of cellular GSH [126] and studies have provided evidence that depletion of GSH leads to activation of NF- $\kappa \mathrm{B}$ [127]. HNE has also been reported to induce $\mathrm{p} 47 \mathrm{phox}$-mediated $\mathrm{NADPH}$ oxidase activity in murine macrophages contributing to oxidative stress [128]. Although the involvement of HNE-induced ROS in HNE-mediated signaling is controversial, studies have shown that HNE-induced mitochondrial damage in cells is primarily due to ROS-generation, which is also a major contributor of vascular damage induced by $\mathrm{HNE}$ [129]. HNE-induced oxidative stress has been shown to be an inducer of endothelial dysfunction. Several studies have demonstrated that treatment with antioxidants such as NAC and mercaptopropionyl glycine, which inhibits oxidative stress, attenuated the HNE-induced loss of endothelial cell function [130, 131]. These studies highlight that HNEinduced oxidative stress as a major player in HNE-induced endothelial cell damage and dysfunction.

Apart from directly regulating $\mathrm{NF}-\kappa \mathrm{B}$, multiple lines of evidence suggest that HNE induces NF- $\kappa \mathrm{B}$-mediated proinflammatory signaling by regulating the activation of major protein kinases such as PKC, p38-MAPK, and JNK [132]. $\mathrm{PKC}$ is an important kinase in mediating HNE signaling. Treatment of RAW 264.7 macrophages with HNE decreases phorbol 12-myristate 13-acetate (PMA)-induced ROS production in a dose- and time-dependent manner by interacting with PKC [133]. Further, MAPK kinases are also reported to play an important role in HNE-induced endothelial dysfunction. In a study using human macrophages, induction of Cox 2 expression was observed upon exposure to HNE. In this study, the authors did not observe any change 


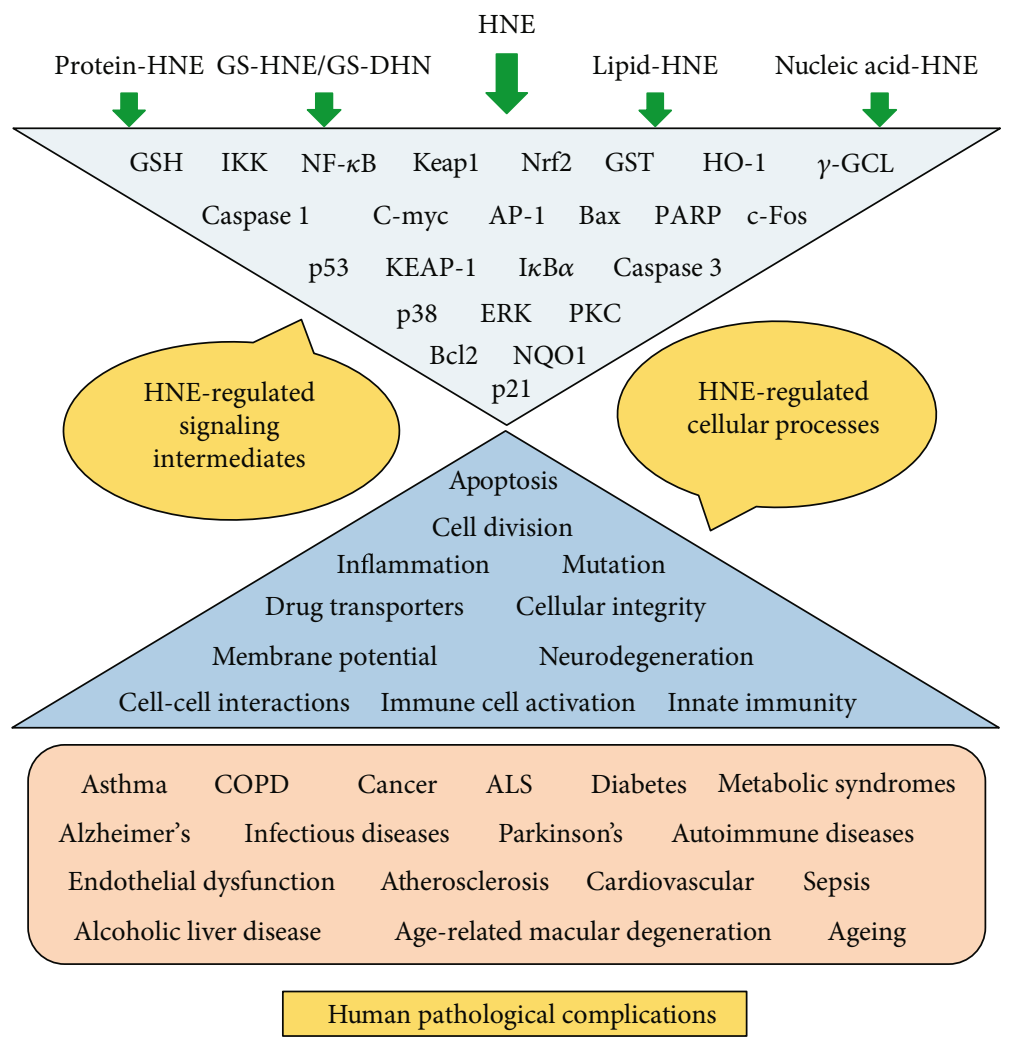

FIGURE 5: Central role of HNE and its metabolites in the regulation of various signaling pathways leading to various human disease pathologies. A summary of important signaling intermediates and cellular processes affect by HNE and its metabolites which can contribute to the pathophysiology of various human disorders are listed.

in the expression of iNOS or NF- $\kappa \mathrm{B}$ but p38-MAPK was found to be an important regulator of HNE-induced inflammatory signaling in macrophages [87]. HNE also alters the balance of calcium ions in cells, which is important for signal transduction mediated by PKC and PI3K isozymes. In human chondrocytes, treatment with HNE induced the HNE-IKK adduct formation leading to inhibition of nuclear translocation of p65 and DNA-binding. Surprisingly, data from the same study show that HNE induces Cox 2 and PGE2 in chondrocytes independent of NF- $\kappa \mathrm{B}$ [118].

Activator protein 1 (AP-1) transcription factor is an important regulator of cellular signaling pathways controlling differentiation, proliferation, and apoptosis. HNE is well known to alter AP-1 transcriptional activity and affects various cellular processes. In rat cortical neurons, HNEinduced AP-1 nuclear translocation and DNA-binding plays an important role in neuronal calcium homeostasis and mitochondrial dysfunction [119]. Furthermore, the regulation of AP-1 activity by HNE has been shown to induce vascular smooth muscle cell proliferation leading to vascular complications [134].

HNE has been shown to be involved in the regulation of both intrinsic and extrinsic apoptotic signaling pathways in cells [19]. Exposure of SK-N-BE neuroblastoma cell lines to HNE induces the expression of p53, p73, p63, p21 and Bax leading to apoptotic cell death [135]. HNE has also been reported to induce p53-mediated apoptosis in the retinal pigment epithelial cells. Using knockout mouse models of
GSTA4-4, Sharma et al., have demonstrated that HNE induces p53-mediated apoptotic signals via p21, Bax, and caspase 3. Inhibiting the cells ability to detoxify HNE leads to HNE-induced phosphorylation and nuclear translocation of p53 and induction of apoptosis [136]. In addition to HNE-induced p53 expression, HNE-mediated cytochrome $\mathrm{C}$ release has been shown to be necessary for HNE-induced apoptosis in macrophages [137].

HNE also induces the activation and phosphorylation of Src kinases. Mass spectrophotometric analysis of HNE-Src interaction showed that HNE interacts with His236, Cys241 and Cys 248 residues of Src. Activation of Src by HNE leads to the expression of inflammatory mediator Cox2 and transcription factor AP-1, via activation of p38MAPK, JNK and ERK1/2 [138]. The HNE-Src adduct formation plays an important role in pro-inflammatory signaling in aged kidneys [139]. HNE also plays an important role in agerelated oxidative stress. Higher plasma levels of HNE has been reported in obese individuals [140]. HNE-induced TNF- $\alpha$ expression in adipocytes was regulated by HNE mediated transcriptional regulation of ETS1 transcription factors [140]. HNE induced inflammation and Cox-2 production in many studies has been reported to be mediated by p38MAPK mediated signaling and activation of ATF-2/CREB1, JNK, c-JUN and AP-1 [20]. Many other transcription factors have been reported to play an important role in HNE-induced vascular endothelial cell dysfunction [141]. Transcription factors such as ATF3 and ATF4, have been 
reported to play an important role in HNE- induced ER stress in endothelial cells. The siRNA mediated ATF4 deletion prevented HNE-induced monocyte adhesion and IL-8 production and exerted protective functions against HNEinduced toxicity in endothelial cells [126].

HNE also plays an important role in cancer-associated inflammation and cancerous progression as evidenced by recent reports highlighting the importance of HNEmediated pro-inflammatory signaling in cancer [142]. HNE is an important second messenger molecule modulating cellular signaling pathways in cancer and mediates cancer cell proliferation, apoptosis, and antioxidant defense [44]. HNE either by extrinsic or intrinsic mechanisms has been reported to facilitate cancerous progression $[9,13,41,44]$. Co-administration of HNE accelerated DSS-induced colitis in mice. Along with the increase in DSS-induced colitis, a significant increase in the expression of pro-inflammatory genes such as IL-6, TLR4, Cox2 along-with infiltration of CD45 and $\mathrm{CD} 45^{+} \mathrm{F} 4 / 80^{+}$immune cells were observed in HNE + DSS treated mice compared to DSS-alone. Treatment with HNE also impairs intestinal barrier function by reducing the colonic expression of occludin protein. Loss of barrier function leads to an increase in the bacterial LPS in the circulation. Further, by using TLR4 null mouse models they have demonstrated that HNE mediates inflammatory signaling in DSS-induced colitis by signaling through TLR4 [143]. Apart from this, analyzing transcript levels of genes altered by HNE in human colorectal carcinoma cells have provided evidence that exposure to HNE induces an alteration in multiple signaling pathways related to antioxidant response, ER stress, apoptosis and cell cycle regulation in a time- and dosedependent manner [144]. Apart from cancer progression, studies also provide evidence that HNE plays an important role in inducing apoptosis in colon carcinoma cells. It has been demonstrated that HNE-induced apoptosis in colon carcinoma cells is mediated by signaling through HSF-1. siRNA-mediated inhibition of HSF-1 prevented HNEinduced cleavage of PARP and caspase 3. Overexpression of Bcl-xl attenuated HNE-induced apoptosis in colon carcinoma cells [145]. HNE also plays an central role in the pathogenesis of inflammatory lung pathologies such as COPD. High levels of HNE-modified proteins have been observed in lung tissues from COPD patients with a positive correlation to inflammation and expression of inflammatory mediators [146]. Recent studies have also demonstrated the importance of HNE in neuronal inflammation and maintenance of neuronal cells. Studies using animal models suggest that HNE reduces neuronal intracellular calcium $\left(\mathrm{Ca}^{+2}\right)$ in CSF and leads to the loss of motor neurons. Calcium levels were also altered in the surviving neurons with no observable morphological alterations. Thus, HNE induces a prominent change in ionic equilibrium in neuronal cells implicating its importance in neurodegenerative diseases $[147,148]$. The importance of HNE and lipid peroxidation products in neuronal biology and neuroinflammation is attaining considerable attention in recent years $[148,149]$. HNE induces the expression of Cox2, PGE2 and IL-6 expression and inhibition of HNE is a beneficial target to attenuate inflammation during osteoarthritis $[150,151]$. Apart from the evidence provided above on the role of HNE in inflammatory pathologies, HNE also plays an important role in the pathogenesis and progression of other inflammatory diseases such as cataract, AMD and COPD [152]. Thus, these studies provide evidence that $\mathrm{HNE}$ is an important mediator of various pro-and antiinflammatory signaling pathways in different cell types (Figure 5) and understanding the cellular signaling pathways regulated by lipid peroxidation-derived aldehydes such as HNE will provide insights into the mechanism of disease and open avenues for the development of new therapeutic strategies in the future.

\section{Conclusions and Future Perspectives}

Recent studies have shown that depending upon the cell type, concentration and adduct formation with macromolecules, HNE could dictate cells to undergo proliferation or death. Interaction of HNE with cellular GSH has been shown to be a major metabolic route for its detoxification as well as intervening the cellular signaling pathways. Recent studies also suggest that HNE and HNE-protein adducts could act as biomarkers of various disease processes. Importantly, HNE metabolizing enzymes such as AR, ALDH1, and GSTs could regulate various antioxidative and pro-inflammatory pathways by generating HNE metabolites such as GS-HNE and GS-DHN which can further act as secondary signaling molecules. These studies opened new dimensions to understand the significance of HNE as well as other lipid aldehydes formed during lipid peroxidation and to understand the significance of aldehyde metabolizing enzymes in the pathophysiology of various diseases. These studies have provided a redox link between lipid aldehyde formation with oxidative stress and immune and inflammatory responses. Most importantly, we have shown that AR that reduces HNE, acrolein and other lipid aldehydes mediate oxidative stress signals initiated by various oxidants such as allergens, bacterial toxins, hyperglycemia, cytokines, and growth factors [56]. In fact, inhibition of AR has been shown to prevent several inflammatory complications including colon cancer, asthma, sepsis, uveitis, and cardiomyopathy $[67,68]$. Thus, the specific use of antioxidants or synthetic inhibitors of HNE metabolizing enzymes that control the intracellular levels of HNE and its GSH-metabolites could be developed as potential therapeutic drug targets. It is a challenge for future research to clearly understand the complex interactions of HNE with various cellular proteins and how the protein-HNE adducts regulate various physiological processes. Further, it is still not clear how HNE commands cell signaling pathways based on a specific cell or tissue type. A better understanding of HNE-adduct formation with cellular macromolecules and identification of new HNE-adducts as potential biomarkers for various human pathologies will help to understand the pathophysiology of disease progression. In addition, identification of new immune and inflammatory response pathways regulated by HNE and its metabolites could help to understand the tissue and organ damage and dysfunction. Further, the use of novel transgenic approaches, metabolomics 
and next-generation sequencing (NGS) could ease the identification of critical signaling pathways intervened by HNE and its metabolites.

\section{Abbreviations}

ADH: Alcohol dehydrogenase

AKR1B1: Aldo-keto reductase family 1 member B1

ALD: $\quad$ Alcoholic liver disease

ALDH: $\quad$ Aldehyde dehydrogenase

AMD: $\quad$ Age-related macular degeneration

AP-1: $\quad$ Activator protein-1

AR: $\quad$ Aldose reductase

ARE: $\quad$ Antioxidant response element

ATF4: $\quad$ Activating transcription factor 4

COPD: $\quad$ Chronic obstructive pulmonary disease

Cox-2: $\quad$ Cyclooxygenase 2

CREB: $\quad$ CAMP response element-binding protein

CSF: Cerebrospinal fluid

Cul3: $\quad$ Cullin3

DHN: 1,4-dihydroxy-2-nonene

DNA: Deoxyribonucleic acid

DSS: Dextran sulfate sodium

EpRE: $\quad$ Electrophile responsive element

ERK: $\quad$ Extracellular signal-regulated kinase

ETS1: $\quad$ ETS proto-oncogene1

GGT: $\quad \gamma$-Glutamyl transpeptidase

GPX: $\quad$ Glutathione peroxidase

GRP-78: $\quad$ Glucose regulated protein 78

GSH: Glutathione

GSSG: $\quad$ Glutathione disulfide

GST: Glutathione-S-transferase

$\mathrm{H}_{2} \mathrm{O}_{2}$ : Hydrogen peroxide

HNA: 4-hydroxy-2-nonanoic acid

HNE: 4-hydroxy-trans-2-nonenal

HO-1: $\quad$ Heme oxygenase-1

HSF-1: Heat shock factor-1

ICAM-1: Intercellular adhesion molecule -1

IKK: I-kappaB kinase

IL-6: Interleukin-6

iNOS: $\quad$ Inducible nitric oxide synthase

I $\kappa \mathrm{B} \alpha$ : $\quad$ Nuclear factor of kappa light polypeptide gene enhancer in B-cells inhibitor- alpha

KEAP-1: Kelch like ECH associated protein 1

LPS: $\quad$ Lipopolysaccharide

MCP-1: $\quad$ Monocyte chemoattractant protein-1

MDA: Malondialdehyde

MRP: $\quad$ Multidrug resistance-associated protein

NAC: $\quad$ N-acetylcysteine

NADPH: Nicotinamide adenine dinucleotide phosphate

NGS: $\quad$ Next-generation sequencing

NF- $\kappa$ B: $\quad$ Nuclear factor kappa-light-chain-enhancer of activated B cells

NQO1: $\quad$ NADPH quinone oxidoreductase 1

Nrf2: $\quad$ NFE2-related nuclear factor 2

OxLDL: Oxidized low-density lipoprotein

p38MAPK: p38 mitogen activated protein kinase

PARP: $\quad$ Poly ADP ribose polymerase

PGE2: $\quad$ Prostaglandin E2
Pgp1: $\quad$ ATP binding cassette subfamily B member 1 (ABCB1)

PKC: $\quad$ Protein kinase $C$

PMA: Phorbol myristate acetate

Prx1: $\quad$ Peroxiredoxin1

PUFA: Polyunsaturated fatty acid

RLIP76: RalA binding protein 1(RALBP1)

ROS: $\quad$ Reactive oxygen species

SOD: $\quad$ Superoxide dismutase

TLR-4: $\quad$ Toll-like receptor 4

TNF- $\alpha$ : Tumor necrosis factor $\alpha$

TPA: Tissue plasminogen activator

Trx: $\quad$ Thioredoxin

UPR: Unfolded protein response

$\gamma$-GCL: $\quad \gamma$-Glutamate cysteine ligase.

\section{Conflicts of Interest}

The authors declare that they have no conflicts of interest.

\section{Acknowledgments}

Supported by funding from NIH/NIDDK grant DK104786.

\section{References}

[1] K. J. Davies, "Oxidative stress, antioxidant defenses, and damage removal, repair, and replacement systems," IUBMB Life, vol. 50, no. 4, pp. 279-289, 2000.

[2] Y. S. Bae, H. Oh, S. G. Rhee, and Y. D. Yoo, "Regulation of reactive oxygen species generation in cell signaling," Molecules and Cells, vol. 32, no. 6, pp. 491-509, 2011.

[3] K. Aquilano, S. Baldelli, and M. R. Ciriolo, "Glutathione: new roles in redox signaling for an old antioxidant," Frontiers in Pharmacology, vol. 5, pp. 196-196, 2014.

[4] T. Fukai and M. Ushio-Fukai, "Superoxide dismutases: role in redox signaling, vascular function, and diseases," Antioxidants \& Redox Signaling, vol. 15, no. 6, pp. 1583-1606, 2011.

[5] P. D. Ray, B.-W. Huang, and Y. Tsuji, "Reactive oxygen species (ROS) homeostasis and redox regulation in cellular signaling," Cellular Signalling, vol. 24, no. 5, pp. 981-990, 2012.

[6] L. A. Pham-Huy, H. He, and C. Pham-Huy, "Free radicals, antioxidants in disease and health," International Journal of Biomedical Science, vol. 4, no. 2, pp. 89-96, 2008.

[7] F. Guéraud, M. Atalay, N. Bresgen et al., "Chemistry and biochemistry of lipid peroxidation products," Free Radical Research, vol. 44, no. 10, pp. 1098-1124, 2010.

[8] M. Mol, L. Regazzoni, A. Altomare et al., "Enzymatic and non-enzymatic detoxification of 4-hydroxynonenal: methodological aspects and biological consequences," Free Radical Biology \& Medicine, vol. 111, pp. 328-344, 2017.

[9] G. Poli, R. J. Schaur, W. G. Siems, and G. Leonarduzzi, “4Hydroxynonenal: A membrane lipid oxidation product of medicinal interest," Medicinal Research Reviews, vol. 28, no. 4, pp. 569-631, 2008.

[10] N. Zarkovic, "4-hydroxynonenal as a bioactive marker of pathophysiological processes," Molecular Aspects of Medicine, vol. 24, no. 4-5, pp. 281-291, 2003.

[11] L. Milkovic, A. Cipak Gasparovic, and N. Zarkovic, "Overview on major lipid peroxidation bioactive factor 4- 
hydroxynonenal as pluripotent growth-regulating factor," Free Radical Research, vol. 49, no. 7, pp. 850-860, 2015.

[12] G. Barrera, S. Pizzimenti, E. S. Ciamporcero et al., "Role of 4hydroxynonenal-protein adducts in human diseases," Antioxidants \& Redox Signaling, vol. 22, no. 18, pp. 1681-1702, 2015.

[13] K. Zarkovic, A. Jakovcevic, and N. Zarkovic, "Contribution of the HNE-immunohistochemistry to modern pathological concepts of major human diseases," Free Radical Biology \& Medicine, vol. 111, pp. 110-126, 2017.

[14] J. P. Castro, T. Jung, T. Grune, and W. Siems, "4-Hydroxynonenal (HNE) modified proteins in metabolic diseases," Free Radical Biology \& Medicine, vol. 111, pp. 309-315, 2017.

[15] B. Sottero, D. Rossin, G. Poli, and F. Biasi, "Lipid oxidation products in the pathogenesis of inflammation-related gut diseases," Current Medicinal Chemistry, vol. 25, no. 11, pp. 1311-1326, 2018.

[16] P. Fleuranceau-Morel, L. Barrier, B. Fauconneau, A. Piriou, and F. Huguet, "Origin of 4-hydroxynonenal incubationinduced inhibition of dopamine transporter and $\mathrm{Na}^{+} / \mathrm{K}^{+}$ adenosine triphosphate in rat striatal synaptosomes," Neuroscience Letters, vol. 277, no. 2, pp. 91-94, 1999.

[17] R. Subramaniam, F. Roediger, B. Jordan et al., "The Lipid Peroxidation Product, 4-Hydroxy-2-trans-Nonenal, Alters the Conformation of Cortical Synaptosomal Membrane Proteins," Journal of Neurochemistry, vol. 69, no. 3, pp. 11611169, 1997.

[18] P. Chaudhary, R. Sharma, A. Sharma et al., "Mechanisms of 4-hydroxy-2-nonenal induced pro- and anti-apoptotic signaling," Biochemistry, vol. 49, no. 29, pp. 6263-6275, 2010.

[19] S. Dalleau, M. Baradat, F. Guéraud, and L. Huc, "Cell death and diseases related to oxidative stress: 4-hydroxynonenal (HNE) in the balance," Cell Death and Differentiation, vol. 20, no. 12, pp. 1615-1630, 2013.

[20] O. Kutuk and H. Basaga, "Apoptosis signalling by 4-hydroxynonenal: a role for JNK-c-Jun/AP-1 pathway," Redox Report, vol. 12, no. 1-2, pp. 30-34, 2007.

[21] H. Feng and B. R. Stockwell, "Unsolved mysteries: how does lipid peroxidation cause ferroptosis?," PLoS Biology, vol. 16, no. $5,2018$.

[22] H. Zhang and H. J. Forman, "Signaling by 4-hydroxy-2nonenal: exposure protocols, target selectivity and degradation," Archives of Biochemistry and Biophysics, vol. 617, pp. 145-154, 2017.

[23] R. Zheng, A. C. Dragomir, V. Mishin et al., "Differential metabolism of 4-hydroxynonenal in liver, lung and brain of mice and rats," Toxicology and Applied Pharmacology, vol. 279, no. 1, pp. 43-52, 2014.

[24] G. Poli and R. J. Schaur, "4-Hydroxynonenal in the pathomechanisms of oxidative stress," IUBMB Life, vol. 50, no. 4, pp. 315-321, 2000.

[25] W. Siems and T. Grune, "Intracellular metabolism of 4hydroxynonenal," Molecular Aspects of Medicine, vol. 24, no. 4-5, pp. 167-175, 2003.

[26] J. A. Doorn and D. R. Petersen, "Covalent modification of amino acid nucleophiles by the lipid peroxidation products 4-hydroxy-2-nonenal and 4-oxo-2-nonenal," Chemical Research in Toxicology, vol. 15, no. 11, pp. 1445-1450, 2002.

[27] J. A. Doorn and D. R. Petersen, "Covalent adduction of nucleophilic amino acids by 4-hydroxynonenal and 4-oxonone- nal," Chemico-Biological Interactions, vol. 143-144, pp. 93100, 2003.

[28] K. Uchida, "4-Hydroxy-2-nonenal: a product and mediator of oxidative stress," Progress in Lipid Research, vol. 42, no. 4, pp. 318-343, 2003.

[29] R. J. Schaur, "Basic aspects of the biochemical reactivity of 4hydroxynonenal," Molecular Aspects of Medicine, vol. 24, no. 4-5, pp. 149-159, 2003.

[30] M. Hashimoto, T. Sibata, H. Wasada, S. Toyokuni, and K. Uchida, "Structural basis of protein-bound endogenous aldehydes. Chemical and immunochemical characterizations of configurational isomers of a 4-hydroxy-2-nonenal-histidine adduct," The Journal of Biological Chemistry, vol. 278, no. 7, pp. 5044-5051, 2003.

[31] B. J. Stewart, J. A. Doorn, and D. R. Petersen, "Residue-specific adduction of tubulin by 4-hydroxynonenal and 4oxononenal causes cross-linking and inhibits polymerization," Chemical Research in Toxicology, vol. 20, no. 8, pp. 1111-1119, 2007.

[32] B. P. Sampey, D. L. Carbone, J. A. Doorn, D. A. Drechsel, and D. R. Petersen, "4-Hydroxy-2-nonenal adduction of extracellular signal-regulated kinase (Erk) and the inhibition of hepatocyte Erk-Est-like protein-1-activating protein-1 signal transduction," Molecular Pharmacology, vol. 71, no. 3, pp. 871-883, 2007.

[33] I. Nakashima, W. Liu, A. A. Akhand et al., "4-hydroxynonenal triggers multistep signal transduction cascades for suppression of cellular functions," Molecular Aspects of Medicine, vol. 24, no. 4-5, pp. 231-238, 2003.

[34] D. A. Ferrington and R. J. Kapphahn, "Catalytic site-specific inhibition of the $20 \mathrm{~S}$ proteasome by 4-hydroxynonenal," FEBS Letters, vol. 578, no. 3, pp. 217-223, 2004.

[35] D. L. Carbone, J. A. Doorn, Z. Kiebler, B. P. Sampey, and D. R. Petersen, "Inhibition of Hsp72-mediated protein refolding by 4-hydroxy-2-nonenal," Chemical Research in Toxicology, vol. 17, no. 11, pp. 1459-1467, 2004.

[36] R. E. Connor, L. J. Marnett, and D. C. Liebler, "Protein-selective capture to analyze electrophile adduction of hsp90 by 4 hydroxynonenal," Chemical Research in Toxicology, vol. 24, no. 8, pp. 1275-1282, 2011.

[37] D. L. Carbone, J. A. Doorn, Z. Kiebler, B. R. Ickes, and D. R. Petersen, "Modification of heat shock protein 90 by 4hydroxynonenal in a rat model of chronic alcoholic liver disease," The Journal of Pharmacology and Experimental Therapeutics, vol. 315, no. 1, pp. 8-15, 2005.

[38] D. Schuler, Budiawan, and E. Eder, "Development of a ${ }^{32} \mathrm{P}$ Postlabeling Method for the Detection of $1, N^{2}$-Propanodeoxyguanosine Adducts of 2-Hexenal in Vivo," Chemical Research in Toxicology, vol. 12, no. 4, pp. 335-340, 1999.

[39] J. Nair, A. Barbin, I. Velic, and H. Bartsch, "Etheno DNAbase adducts from endogenous reactive species," Mutation Research, vol. 424, no. 1-2, pp. 59-69, 1999.

[40] G. M. Karlhuber, H. C. Bauer, and P. M. Eckl, "Cytotoxic and genotoxic effects of 4-hydroxynonenal in cerebral endothelial cells," Mutation Research/Fundamental and Molecular Mechanisms of Mutagenesis, vol. 381, no. 2, pp. 209-216, 1997.

[41] Z. Feng, W. Hu, and M.-S. Tang, "Trans-4-hydroxy-2-nonenal inhibits nucleotide excision repair in human cells: a possible mechanism for lipid peroxidation-induced carcinogenesis," Proceedings of the National Academy of Sciences of the United States of America, vol. 101, no. 23, pp. 8598-8602, 2004. 
[42] I. A. Blair, "DNA adducts with lipid peroxidation products," The Journal of Biological Chemistry, vol. 283, no. 23, pp. 15545-15549, 2008.

[43] W. G. Siems, H. Zollner, T. Grune, and H. Esterbauer, "Metabolic fate of 4-hydroxynonenal in hepatocytes: 1,4-dihydroxynonene is not the main product," Journal of Lipid Research, vol. 38, no. 3, pp. 612-622, 1997.

[44] F. Gueraud, "4-Hydroxynonenal metabolites and adducts in pre-carcinogenic conditions and cancer," Free Radical Biology \& Medicine, vol. 111, pp. 196-208, 2017.

[45] R. Sharma, Y. Yang, A. Sharma et al., "Mechanisms and physiological significance of the transport of the glutathione conjugate of 4-hydroxynonenal in human lens epithelial cells," Investigative Ophthalmology \& Visual Science, vol. 44, no. 8, pp. 3438-3449, 2003.

[46] S. Awasthi, S. S. Singhal, R. Sharma, P. Zimniak, and Y. C. Awasthi, "Transport of glutathione conjugates and chemotherapeutic drugs by RLIP76 (RALBP1): A novel link between G-protein and tyrosine kinase signaling and drug resistance," International Journal of Cancer, vol. 106, no. 5, pp. 635-646, 2003.

[47] R. B. Tjalkens, L. W. Cook, and D. R. Petersen, "Formation and export of the glutathione conjugate of 4-hydroxy-2, 3E-nonenal (4-HNE) in hepatoma cells," Archives of Biochemistry and Biophysics, vol. 361, no. 1, pp. 113-119, 1999.

[48] A. E. Mitchell, D. Morin, M. W. Lame, and A. D. Jones, "Purification, mass spectrometric characterization, and covalent modification of murine glutathione S-transferases," Chemical Research in Toxicology, vol. 8, no. 8, pp. 1054-1062, 1995.

[49] D. L. Vander Jagt, L. A. Hunsaker, T. J. Vander Jagt et al., "Inactivation of glutathione reductase by 4-hydroxynonenal and other endogenous aldehydes," Biochemical Pharmacology, vol. 53, no. 8, pp. 1133-1140, 1997.

[50] R.-M. Liu, L. Gao, J. Choi, and H. J. Forman, " $\gamma$-Glutamylcysteine synthetase: mRNA stabilization and independent subunit transcription by 4-hydroxy-2-nonenal," American Journal of Physiology-Lung Cellular and Molecular Physiology, vol. 275, no. 5, pp. L861-L869, 1998.

[51] K. Berhane, M. Widersten, A. Engstrom, J. W. Kozarich, and B. Mannervik, "Detoxication of base propenals and other alpha, beta-unsaturated aldehyde products of radical reactions and lipid peroxidation by human glutathione transferases," Proceedings of the National Academy of Sciences of the United States of America, vol. 91, no. 4, pp. 1480-1484, 1994.

[52] D. P. Hartley, J. A. Ruth, and D. R. Petersen, "The hepatocellular metabolism of 4-hydroxynonenal by alcohol dehydrogenase, aldehyde dehydrogenase, and glutathione Stransferase," Archives of Biochemistry and Biophysics, vol. 316, no. 1, pp. 197-205, 1995.

[53] L. M. Balogh and W. M. Atkins, "Interactions of glutathione transferases with 4-hydroxynonenal," Drug Metabolism Reviews, vol. 43, no. 2, pp. 165-178, 2011.

[54] Y. C. Awasthi, K. V. Ramana, P. Chaudhary, S. K. Srivastava, and S. Awasthi, "Regulatory roles of glutathione-Stransferases and 4-hydroxynonenal in stress-mediated signaling and toxicity," Free Radical Biology and Medicine, vol. 111, pp. 235-243, 2017.

[55] Y. C. Awasthi, R. Sharma, J. Z. Cheng et al., "Role of 4hydroxynonenal in stress-mediated apoptosis signaling,"
Molecular Aspects of Medicine, vol. 24, no. 4-5, pp. 219-230, 2003.

[56] K. V. Ramana, “ALDOSE REDUCTASE: new insights for an old enzyme," Biomolecular Concepts, vol. 2, no. 1-2, pp. 103114, 2011.

[57] S. Spycher, S. Tabataba-Vakili, V. B. O'Donnell, L. Palomba, and A. Azzi, "4-hydroxy-2, 3-trans-nonenal induces transcription and expression of aldose reductase," Biochemical and Biophysical Research Communications, vol. 226, no. 2, pp. 512-516, 1996.

[58] M. E. Burczynski, G. R. Sridhar, N. T. Palackal, and T. M. Penning, "The reactive oxygen species-and Michael acceptor-inducible human aldo-keto reductase AKR1C1 reduces the alpha,beta-unsaturated aldehyde 4-hydroxy-2nonenal to 1,4-dihydroxy-2-nonene," The Journal of Biological Chemistry, vol. 276, no. 4, pp. 2890-2897, 2001.

[59] S. Choudhary, S. Srivastava, T. Xiao, U. P. Andley, S. K. Srivastava, and N. H. Ansari, "Metabolism of lipid derived aldehyde, 4-hydroxynonenal in human lens epithelial cells and rat lens," Investigative Ophthalmology \& Visual Science, vol. 44, no. 6, pp. 2675-2682, 2003.

[60] S. Srivastava, B. L. Dixit, J. Cai et al., "Metabolism of lipid peroxidation product, 4-hydroxynonenal (HNE) in rat erythrocytes: role of aldose reductase," Free Radical Biology \& Medicine, vol. 29, no. 7, pp. 642-651, 2000.

[61] S. Srivastava, S. Q. Liu, D. J. Conklin, A. Zacarias, S. K. Srivastava, and A. Bhatnagar, "Involvement of aldose reductase in the metabolism of atherogenic aldehydes," Chemico-Biological Interactions, vol. 130-132, no. 1-3, pp. 563-571, 2001.

[62] S. Srivastava, A. Chandra, L. F. Wang et al., "Metabolism of the lipid peroxidation product, 4-hydroxy-trans-2-nonenal, in isolated perfused rat heart," The Journal of Biological Chemistry, vol. 273, no. 18, pp. 10893-10900, 1998.

[63] S. Srivastava, S. J. Watowich, J. M. Petrash, S. K. Srivastava, and A. Bhatnagar, "Structural and kinetic determinants of aldehyde reduction by aldose reductase," Biochemistry, vol. 38, no. 1, pp. 42-54, 1999.

[64] B. L. Dixit, G. K. Balendiran, S. J. Watowich et al., "Kinetic and structural characterization of the glutathione-binding site of aldose reductase," The Journal of Biological Chemistry, vol. 275, no. 28, pp. 21587-21595, 2000.

[65] R. Singh, M. A. White, K. V. Ramana et al., "Structure of a glutathione conjugate bound to the active site of aldose reductase," Proteins: Structure, Function, and Bioinformatics, vol. 64, no. 1, pp. 101-110, 2006.

[66] U. C. Yadav and K. V. Ramana, "Regulation of NF- $\kappa$ BInduced Inflammatory Signaling by Lipid PeroxidationDerived Aldehydes," Oxidative Medicine and Cellular Longevity, vol. 2013, Article ID 690545, 2013.

[67] K. V. Ramana and S. K. Srivastava, "Aldose reductase: a novel therapeutic target for inflammatory pathologies," The International Journal of Biochemistry \& Cell Biology, vol. 42, no. 1, pp. 17-20, 2010.

[68] R. Tammali, S. K. Srivastava, and K. V. Ramana, "Targeting aldose reductase for the treatment of cancer," Current Cancer Drug Targets, vol. 11, no. 5, pp. 560-571, 2011.

[69] T. Grune, P. Michel, N. Sitte et al., "Increased levels of 4hydroxynonenal modified proteins in plasma of children with autoimmune diseases," Free Radical Biology and Medicine, vol. 23, no. 3, pp. 357-360, 1997. 
[70] S. Kamimura, K. Gaal, R. S. Britton, B. R. Bacon, G. Triadafilopoulos, and H. Tsukamoto, "Increased 4hydroxynonenal levels in experimental alcoholic liver disease: association of lipid peroxidation with liver fibrogenesis," Hepatology, vol. 16, no. 2, pp. 448-453, 1992.

[71] H. Tsukamoto, W. Horne, S. Kamimura et al., "Experimental liver cirrhosis induced by alcohol and iron," The Journal of Clinical Investigation, vol. 96, no. 1, pp. 620-630, 1995.

[72] C. M. Spickett, "The lipid peroxidation product 4-hydroxy-2nonenal: advances in chemistry and analysis," Redox Biology, vol. 1, no. 1, pp. 145-152, 2013.

[73] H. Motohashi and M. Yamamoto, "Nrf2-Keap1 defines a physiologically important stress response mechanism," Trends in Molecular Medicine, vol. 10, no. 11, pp. 549-557, 2004.

[74] T. Suzuki and M. Yamamoto, "Molecular basis of the Keap1Nrf2 system," Free Radical Biology and Medicine, vol. 88, pp. 93-100, 2015.

[75] A. Kobayashi, M. I. Kang, Y. Watai et al., "Oxidative and electrophilic stresses activate Nrf2 through inhibition of ubiquitination activity of Keap1," Molecular and Cellular Biology, vol. 26, no. 1, pp. 221-229, 2006.

[76] A. T. Dinkova-Kostova, W. D. Holtzclaw, R. N. Cole et al., "Direct evidence that sulfhydryl groups of Keap1 are the sensors regulating induction of phase 2 enzymes that protect against carcinogens and oxidants," Proceedings of the National Academy of Sciences of the United States of America, vol. 99, no. 18, pp. 11908-11913, 2002.

[77] M. McMahon, D. J. Lamont, K. A. Beattie, and J. D. Hayes, "Keap1 perceives stress via three sensors for the endogenous signaling molecules nitric oxide, zinc, and alkenals," Proceedings of the National Academy of Sciences of the United States of America, vol. 107, no. 44, pp. 18838-18843, 2010.

[78] S. Numazawa, M. Ishikawa, A. Yoshida, S. Tanaka, and T. Yoshida, "Atypical protein kinase $\mathrm{C}$ mediates activation of NF-E2-related factor 2 in response to oxidative stress," American Journal of Physiology. Cell Physiology, vol. 285, no. 2, pp. C334-C342, 2003.

[79] J. Chen, L. Wang, Y. Chen, P. Sternberg, and J. Cai, "Phosphatidylinositol 3 kinase pathway and 4-hydroxy-2nonenal-induced oxidative injury in the RPE," Investigative Ophthalmology \& Visual Science, vol. 50, no. 2, pp. 936-942, 2009.

[80] Z. Sun, Z. Huang, and D. D. Zhang, "Phosphorylation of Nrf2 at multiple sites by MAP kinases has a limited contribution in modulating the Nrf2-dependent antioxidant response," PLoS One, vol. 4, no. 8, pp. e6588-e6588, 2009.

[81] M. Zhang, C. An, Y. Gao, R. K. Leak, J. Chen, and F. Zhang, "Emerging roles of Nrf2 and phase II antioxidant enzymes in neuroprotection," Progress in Neurobiology, vol. 100, pp. 30-47, 2013.

[82] T. Nguyen, P. Nioi, and C. B. Pickett, "The Nrf2-antioxidant response element signaling pathway and its activation by oxidative stress," The Journal of Biological Chemistry, vol. 284, no. 20, pp. 13291-13295, 2009.

[83] Q. Ma, "Role of nrf2 in oxidative stress and toxicity," Annual Review of Pharmacology and Toxicology, vol. 53, no. 1, pp. 401-426, 2013.

[84] S. S. Singhal, S. P. Singh, P. Singhal, D. Horne, J. Singhal, and S. Awasthi, "Antioxidant role of glutathione S-transferases: 4-
Hydroxynonenal, a key molecule in stress-mediated signaling," Toxicology and Applied Pharmacology, vol. 289, no. 3, pp. 361-370, 2015.

[85] D. M. Miller, I. N. Singh, J. A. Wang, and E. D. Hall, "Administration of the Nrf2-ARE activators sulforaphane and carnosic acid attenuates 4-hydroxy-2-nonenal-induced mitochondrial dysfunction ex vivo," Free Radical Biology \& Medicine, vol. 57, pp. 1-9, 2013.

[86] Y. Huang, W. Li, and A.-N. T. Kong, "Anti-oxidative stress regulator NF-E2-related factor 2 mediates the adaptive induction of antioxidant and detoxifying enzymes by lipid peroxidation metabolite 4-hydroxynonenal," Cell \& Bioscience, vol. 2, no. 1, pp. 40-40, 2012.

[87] T. Kumagai, N. Matsukawa, Y. Kaneko, Y. Kusumi, M. Mitsumata, and K. Uchida, "A lipid peroxidationderived inflammatory mediator: identification of 4-hydroxy2-nonenal as a potential inducer of cyclooxygenase-2 in macrophages," The Journal of Biological Chemistry, vol. 279, no. 46, pp. 48389-48396, 2004.

[88] S. Gargiulo, P. Gamba, G. Testa et al., "Relation between TLR4/NF- $\kappa \mathrm{B}$ signaling pathway activation by $27-$ hydroxycholesterol and 4-hydroxynonenal, and atherosclerotic plaque instability," Aging Cell, vol. 14, no. 4, pp. 569581, 2015.

[89] S. Gargiulo, G. Testa, P. Gamba, E. Staurenghi, G. Poli, and G. Leonarduzzi, "Oxysterols and 4-hydroxy-2-nonenal contribute to atherosclerotic plaque destabilization," Free Radical Biology and Medicine, vol. 111, pp. 140-150, 2017.

[90] T. Ishii, K. Itoh, E. Ruiz et al., "Role of Nrf2 in the regulation of CD36 and stress protein expression in murine macrophages: activation by oxidatively modified LDL and 4-hydroxynonenal," Circulation Research, vol. 94, no. 5, pp. 609-616, 2004.

[91] R. C. Siow, T. Ishii, and G. E. Mann, "Modulation of antioxidant gene expression by 4-hydroxynonenal: atheroprotective role of the Nrf2/ARE transcription pathway," Redox Report, vol. 12, no. 1-2, pp. 11-15, 2007.

[92] A. Negre-Salvayre, S. Garoby-Salom, A. Swiader, M. Rouahi, M. Pucelle, and R. Salvayre, "Proatherogenic effects of 4hydroxynonenal," Free Radical Biology \& Medicine, vol. 111, pp. 127-139, 2017.

[93] M. Tanito, M. P. Agbaga, and R. E. Anderson, "Upregulation of thioredoxin system via Nrf2-antioxidant responsive element pathway in adaptive-retinal neuroprotection in vivo and in vitro," Free Radical Biology \& Medicine, vol. 42, no. 12, pp. 1838-1850, 2007.

[94] P. E. Malone and M. R. Hernandez, "4-Hydroxynonenal, a product of oxidative stress, leads to an antioxidant response in optic nerve head astrocytes," Experimental Eye Research, vol. 84, no. 3, pp. 444-454, 2007.

[95] Y. Huang, W. Li, Z. Y. Su, and A. N. T. Kong, "The complexity of the Nrf2 pathway: beyond the antioxidant response," The Journal of Nutritional Biochemistry, vol. 26, no. 12, pp. 1401-1413, 2015.

[96] D. S. Backos, K. S. Fritz, J. R. Roede, D. R. Petersen, and C. C. Franklin, "Posttranslational modification and regulation of glutamate-cysteine ligase by the $\alpha, \beta$-unsaturated aldehyde 4-hydroxy-2-nonenal," Free Radical Biology and Medicine, vol. 50, no. 1, pp. 14-26, 2011.

[97] O. W. Griffith and R. T. Mulcahy, "The Enzymes of Glutathione Synthesis: $\gamma$-Glutamylcysteine Synthetase," Advances in 
Enzymology and Related Areas of Molecular Biology, vol. 73, pp. 209-267, 1999.

[98] H. Zhang, H. Liu, D. A. Dickinson et al., " $\gamma$-Glutamyl transpeptidase is induced by 4-hydroxynonenal via EpRE/Nrf2 signaling in rat epithelial type II cells," Free Radical Biology \& Medicine, vol. 40, no. 8, pp. 1281-1292, 2006.

[99] H. Zhang, H. Liu, K. E. Iles et al., "4-Hydroxynonenal induces rat $\gamma$-Glutamyl transpeptidase through mitogen-activated protein kinase-mediated electrophile response element/nuclear factor erythroid 2-related factor 2 signaling," American Journal of Respiratory Cell and Molecular Biology, vol. 34, no. 2, pp. 174-181, 2006.

[100] D. A. Dickinson, K. E. Iles, N. Watanabe et al., "4-hydroxynonenal induces glutamate cysteine ligase through JNK in HBE1 cells," Free Radical Biology \& Medicine, vol. 33, no. 7, pp. 974-987, 2002.

[101] K. E. Iles and R. M. Liu, "Mechanisms of glutamate cysteine ligase (GCL) induction by 4-hydroxynonenal," Free Radical Biology \& Medicine, vol. 38, no. 5, pp. 547-556, 2005.

[102] Z. H. Chen, Y. Saito, Y. Yoshida, A. Sekine, N. Noguchi, and E. Niki, "4-Hydroxynonenal induces adaptive response and enhances PC12 cell tolerance primarily through induction of thioredoxin reductase 1 via activation of Nrf2," The Journal of Biological Chemistry, vol. 280, no. 51, pp. 4192141927, 2005.

[103] K. E. Iles, D. A. Dickinson, A. F. Wigley, N. E. Welty, V. Blank, and H. J. Forman, "HNE increases HO-1 through activation of the ERK pathway in pulmonary epithelial cells," Free Radical Biology \& Medicine, vol. 39, no. 3, pp. 355-364, 2005.

[104] H. Raza and A. John, "4-hydroxynonenal induces mitochondrial oxidative stress, apoptosis and expression of glutathione S-transferase A4-4 and cytochrome P450 2E1 in PC12 cells," Toxicology and Applied Pharmacology, vol. 216, no. 2, pp. 309-318, 2006.

[105] M. H. Lin, J. H. Yen, C. Y. Weng, L. Wang, C. L. Ha, and M. J. $\mathrm{Wu}$, "Lipid peroxidation end product 4-hydroxy-trans-2nonenal triggers unfolded protein response and heme oxygenase-1 expression in PC12 cells: roles of ROS and MAPK pathways," Toxicology, vol. 315, pp. 24-37, 2014.

[106] M. J. Morgan and Z.-g. Liu, "Crosstalk of reactive oxygen species and NF- $\kappa \mathrm{B}$ signaling," Cell Research, vol. 21, no. 1, pp. 103-115, 2011.

[107] S. Park, B. Sung, E. J. Jang et al., "Inhibitory action of salicylideneamino-2-thiophenol on NF- $\kappa \mathrm{B}$ signaling cascade and cyclooxygenase-2 in HNE-treated endothelial cells," Archives of Pharmacal Research, vol. 36, no. 7, pp. 880-889, 2013.

[108] M. Y. Selcuk, B. Aygen, A. Dogukan et al., "Chromium picolinate and chromium histidinate protects against renal dysfunction by modulation of NF- $\kappa$ B pathway in high-fat diet fed and Streptozotocin-induced diabetic rats," Nutrition \& Metabolism, vol. 9, no. 1, p. 30, 2012.

[109] G. Valacchi, C. Sticozzi, G. Belmonte et al., "Vitamin Ccompound mixtures prevent ozone-induced oxidative damage in human keratinocytes as initial assessment of pollution protection," PLoS One, vol. 10, no. 8, 2015.

[110] I. Potočnjak, M. Škoda, E. Pernjak-Pugel, M. P. Peršić, and R. Domitrović, "Oral administration of oleuropein attenuates cisplatin-induced acute renal injury in mice through inhibition of ERK signaling," Molecular Nutrition \& Food Research, vol. 60 , no. 3, pp. 530-541, 2016.
[111] K. Venkatachalam, S. D. Prabhu, V. S. Reddy, W. H. Boylston, A. J. Valente, and B. Chandrasekar, "Neutralization of interleukin-18 ameliorates ischemia/reperfusioninduced myocardial injury," The Journal of Biological Chemistry, vol. 284, no. 12, pp. 7853-7865, 2009.

[112] H. Sonowal, P. Pal, K. Shukla, A. Saxena, S. K. Srivastava, and K. V. Ramana, "Aldose reductase inhibitor, fidarestat prevents doxorubicin-induced endothelial cell death and dysfunction," Biochemical Pharmacology, vol. 150, pp. 181-190, 2018.

[113] A. C. Timucin and H. Basaga, "Pro-apoptotic effects of lipid oxidation products: $\mathrm{HNE}$ at the crossroads of NF- $\kappa \mathrm{B}$ pathway and anti-apoptotic Bcl-2," Free Radical Biology and Medicine, vol. 111, pp. 209-218, 2017.

[114] S. Page, C. Fischer, B. Baumgartner et al., "4-Hydroxynonenal prevents NF-kappaB activation and tumor necrosis factor expression by inhibiting IkappaB phosphorylation and subsequent proteolysis," The Journal of Biological Chemistry, vol. 274, no. 17, pp. 11611-11618, 1999.

[115] C. Ji, K. R. Kozak, and L. J. Marnett, "I $\kappa$ B Kinase, a Molecular Target for Inhibition by 4-Hydroxy-2-nonenal," The Journal of Biological Chemistry, vol. 276, no. 21, pp. 18223-18228, 2001.

[116] X. Dou, S. Li, Z. Wang et al., "Inhibition of NF- $\kappa$ B activation by 4 -Hydroxynonenal contributes to liver injury in a mouse model of alcoholic liver disease," The American Journal of Pathology, vol. 181, no. 5, pp. 1702-1710, 2012.

[117] S. W. Luckey, M. Taylor, B. P. Sampey, R. I. Scheinman, and D. R. Petersen, "4-Hydroxynonenal Decreases Interleukin-6 Expression and Protein Production in Primary Rat Kupffer Cells by Inhibiting Nuclear Factor- $\kappa \mathrm{B}$ Activation," The Journal of Pharmacology and Experimental Therapeutics, vol. 302, no. 1, pp. 296-303, 2002.

[118] F. Vaillancourt, B. Morquette, Q. Shi et al., "Differential regulation of cyclooxygenase- 2 and inducible nitric oxide synthase by 4 -hydroxynonenal in human osteoarthritic chondrocytes through ATF-2/CREB-1 transactivation and concomitant inhibition of NF- $\kappa$ B signaling cascade," Journal of Cellular Biochemistry, vol. 100, no. 5, pp. 1217-1231, 2007.

[119] S. Camandola, G. Poli, and M. P. Mattson, "The lipid peroxidation product 4-hydroxy-2, 3-nonenal increases AP-1binding activity through caspase activation in neurons," Journal of Neurochemistry, vol. 74, no. 1, pp. 159-168, 2000.

[120] J. Ruef, M. Moser, C. Bode, W. Kübler, and M. S. Runge, “4Hydroxynonenal induces apoptosis, NF- $\kappa \mathrm{B}$-activation and formation of 8-isoprostane in vascular smooth nmuscle cells," Basic Research in Cardiology, vol. 96, no. 2, pp. 143150, 2001.

[121] S. J. Lee, K. W. Seo, M. R. Yun et al., "4-Hydroxynonenal enhances MMP-2 production in vascular smooth muscle cells via mitochondrial ROS-mediated activation of the Akt/NF$\kappa \mathrm{B}$ signaling pathways," Free Radical Biology \& Medicine, vol. 45, no. 10, pp. 1487-1492, 2008.

[122] S. J. Lee, C. E. Kim, K. W. Seo, and C. D. Kim, "HNE-induced 5 -LO expression is regulated by NF- $\kappa \mathrm{B} / \mathrm{ERK}$ and Sp1/p38 MAPK pathways via EGF receptor in murine macrophages," Cardiovascular Research, vol. 88, no. 2, pp. 352-359, 2010.

[123] K. V. Ramana, A. B. M. Reddy, R. Tammali, and S. K. Srivastava, "Aldose reductase mediates endotoxin-induced production of nitric oxide and cytotoxicity in murine macrophages," Free Radical Biology and Medicine, vol. 42, no. 8, pp. 1290-1302, 2007. 
[124] G. Yin, Y. Wang, X. M. Cen, M. Yang, Y. Liang, and Q. B. Xie, "Lipid Peroxidation-Mediated Inflammation Promotes Cell Apoptosis through Activation of NF- $\kappa$ B Pathway in Rheumatoid Arthritis Synovial Cells," Mediators of Inflammation, vol. 2015, Article ID 460310, 2015.

[125] U. Herbst, M. Toborek, S. Kaiser, M. P. Mattson, and B. Hennig, "4-Hydroxynonenal induces dysfunction and apoptosis of cultured endothelial cells," Journal of Cellular Physiology, vol. 181, no. 2, pp. 295-303, 1999.

[126] E. Vladykovskaya, S. D. Sithu, P. Haberzettl et al., "Lipid peroxidation product 4-hydroxy-trans-2-nonenal causes endothelial activation by inducing endoplasmic reticulum stress," The Journal of Biological Chemistry, vol. 287, no. 14, pp. 11398-11409, 2012.

[127] C. L. Hammond, T. K. Lee, and N. Ballatori, "Novel roles for glutathione in gene expression, cell death, and membrane transport of organic solutes," Journal of Hepatology, vol. 34, no. 6, pp. 946-954, 2001.

[128] M. R. Yun, H. M. Park, K. W. Seo, S. J. Lee, D. S. Im, and C. D. Kim, "5-lipoxygenase plays an essential role in 4-HNEenhanced ROS production in murine macrophages via activation of NADPH oxidase," Free Radical Research, vol. 44, no. 7, pp. 742-750, 2010.

[129] J. Y. Lee, G. Y. Jung, H. J. Heo et al., "4-Hydroxynonenal induces vascular smooth muscle cell apoptosis through mitochondrial generation of reactive oxygen species," Toxicology Letters, vol. 166, no. 3, pp. 212-221, 2006.

[130] P. V. Usatyuk and V. Natarajan, "Role of mitogen-activated protein kinases in 4-hydroxy-2-nonenal-induced actin remodeling and barrier function in endothelial cells," The Journal of Biological Chemistry, vol. 279, no. 12, pp. 1178911797, 2004.

[131] P. V. Usatyuk, N. L. Parinandi, and V. Natarajan, "Redox regulation of 4-hydroxy-2-nonenal-mediated endothelial barrier dysfunction by focal adhesion, adherens, and tight junction proteins," The Journal of Biological Chemistry, vol. 281, no. 46, pp. 35554-35566, 2006.

[132] K. Uchida, M. Shiraishi, Y. Naito, Y. Torii, Y. Nakamura, and T. Osawa, "Activation of stress signaling pathways by the end product of lipid peroxidation. 4-hydroxy-2-nonenal is a potential inducer of intracellular peroxide production," The Journal of Biological Chemistry, vol. 274, no. 4, pp. 22342242, 1999.

[133] R. S. Harry, L. A. Hiatt, D. W. Kimmel et al., "Metabolic impact of 4-Hydroxynonenal on macrophage-like RAW 264.7 function and activation," Chemical Research in Toxicology, vol. 25, no. 8, pp. 1643-1651, 2012.

[134] K. V. Ramana, A. Bhatnagar, S. Srivastava et al., "Mitogenic responses of vascular smooth muscle cells to lipid peroxidation-derived aldehyde 4-hydroxy-trans-2-nonenal (HNE): role of aldose reductase-catalyzed reduction of the HNE-glutathione conjugates in regulating cell growth," The Journal of Biological Chemistry, vol. 281, no. 26, pp. 1765217660, 2006.

[135] S. Laurora, E. Tamagno, F. Briatore et al., "4-Hydroxynonenal modulation of p53 family gene expression in the SK-N-BE neuroblastoma cell line," Free Radical Biology and Medicine, vol. 38, no. 2, pp. 215-225, 2005.

[136] A. Sharma, R. Sharma, P. Chaudhary et al., "4-Hydroxynonenal induces p53-mediated apoptosis in retinal pigment epithelial cells," Archives of Biochemistry and Biophysics, vol. 480 , no. 2 , pp. 85-94, 2008.
[137] R. L. Haynes, B. Brune, and A. J. Townsend, "Apoptosis in RAW 264.7 cells exposed to 4-hydroxy-2-nonenal: dependence on cytochrome $\mathrm{C}$ release but not p53 accumulation," Free Radical Biology \& Medicine, vol. 30, no. 8, pp. 884894, 2001.

[138] E. J. Jang, H. O. Jeong, D. Park et al., "Src tyrosine kinase activation by 4 -Hydroxynonenal upregulates p38, ERK/AP1 signaling and COX-2 expression in YPEN-1 cells," PLoS One, vol. 10, no. 10, 2015.

[139] E. J. Jang, D. H. Kim, B. Lee et al., "Activation of proinflammatory signaling by 4-hydroxynonenal-Src adducts in aged kidneys," Oncotarget, vol. 7, no. 32, pp. 5086450874, 2016.

[140] X. M. Zhang, L. Guo, X. Huang, Q. M. Li, and M. H. Chi, “4Hydroxynonenal Regulates TNF- $\alpha$ Gene Transcription Indirectly via ETS1 and microRNA-29b in Human Adipocytes Induced From Adipose Tissue-Derived Stromal Cells," The Anatomical Record, vol. 299, no. 8, pp. 1145-1152, 2016.

[141] S. J. Chapple, X. Cheng, and G. E. Mann, "Effects of 4hydroxynonenal on vascular endothelial and smooth muscle cell redox signaling and function in health and disease," Redox Biology, vol. 1, pp. 319-331, 2013.

[142] K. Uchida, "HNE as an inducer of COX-2," Free Radical Biology and Medicine, vol. 111, pp. 169-172, 2017.

[143] Y. Wang, W. Wang, H. Yang, D. Shao, X. Zhao, and G. Zhang, "Intraperitoneal injection of 4-hydroxynonenal (4-HNE), a lipid peroxidation product, exacerbates colonic inflammation through activation of toll-like receptor 4 signaling," Free Radical Biology and Medicine, vol. 131, pp. 237-242, 2019.

[144] J. D. West and L. J. Marnett, "Alterations in gene expression induced by the lipid peroxidation product, 4-hydroxy-2nonenal," Chemical Research in Toxicology, vol. 18, no. 11, pp. 1642-1653, 2005.

[145] A. T. Jacobs and L. J. Marnett, "Heat shock factor 1 attenuates 4-Hydroxynonenal-mediated apoptosis: critical role for heat shock protein 70 induction and stabilization of Bcl-XL," The Journal of Biological Chemistry, vol. 282, no. 46, pp. 33412-33420, 2007.

[146] I. Rahman, A. A. M. van Schadewijk, A. J. L. Crowther et al., "4-Hydroxy-2-nonenal, a specific lipid peroxidation product, is elevated in lungs of patients with chronic obstructive pulmonary disease," American Journal of Respiratory and Critical Care Medicine, vol. 166, no. 4, pp. 490495, 2002.

[147] L. Vigh, R. G. Smith, J. Soós, J. I. Engelhardt, S. H. Appel, and L. Siklós, "Sublethal dose of 4-hydroxynonenal reduces intracellular calcium in surviving motor neurons in vivo," Acta Neuropathologica, vol. 109, no. 6, pp. 567-575, 2005.

[148] K. Zarkovic, "4-hydroxynonenal and neurodegenerative diseases," Molecular Aspects of Medicine, vol. 24, no. 4-5, pp. 293-303, 2003.

[149] M. Shichiri, "The role of lipid peroxidation in neurological disorders," Journal of Clinical Biochemistry and Nutrition, vol. 54, no. 3, pp. 151-160, 2014.

[150] S.-H. Chen, H. Fahmi, Q. Shi, and M. Benderdour, "Regulation of microsomal prostaglandin E2 synthase-1 and 5-lipoxygenase-activating protein/5-lipoxygenase by 4-hydroxynonenal in human osteoarthritic chondrocytes," Arthritis Research \& Therapy, vol. 12, no. 1, pp. R21R21, 2010. 
[151] Q. Shi, F. Vaillancourt, V. Côté et al., "Alterations of metabolic activity in human osteoarthritic osteoblasts by lipid peroxidation end product 4-hydroxynonenal," Arthritis Research \& Therapy, vol. 8, no. 6, pp. R159-R159, 2006.

[152] M. Shoeb, N. H. Ansari, S. K. Srivastava, and K. V. Ramana, "4-Hydroxynonenal in the pathogenesis and progression of human diseases," Current Medicinal Chemistry, vol. 21, no. 2, pp. 230-237, 2014. 


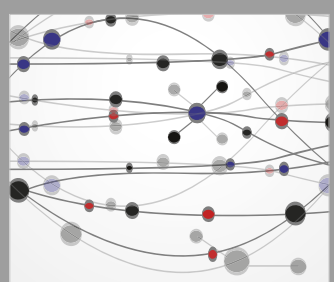

The Scientific World Journal
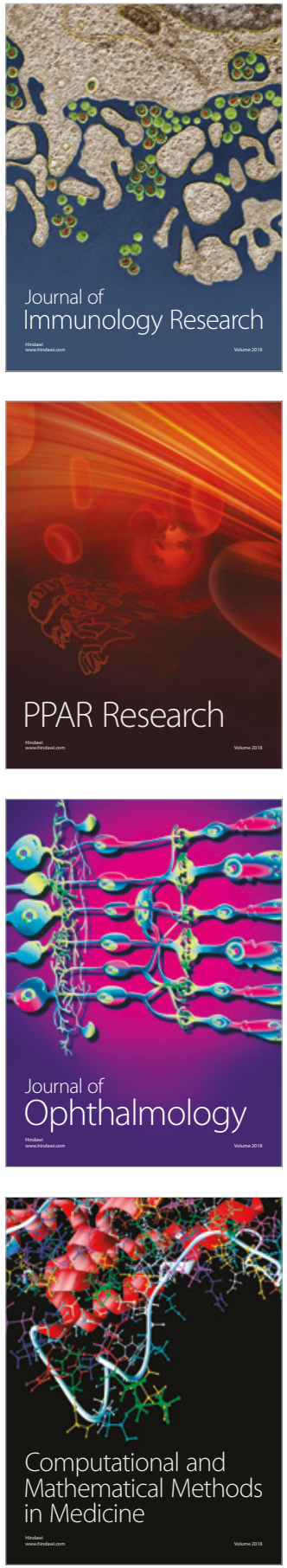

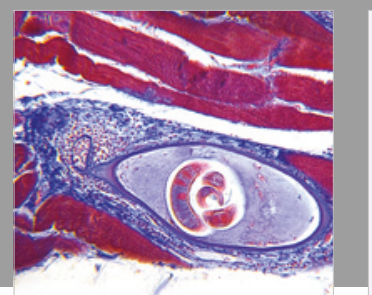

Gastroenterology Research and Practice

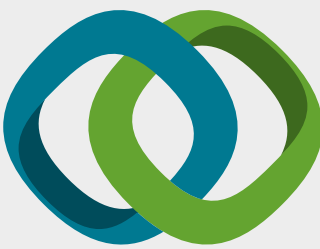

\section{Hindawi}

Submit your manuscripts at

www.hindawi.com
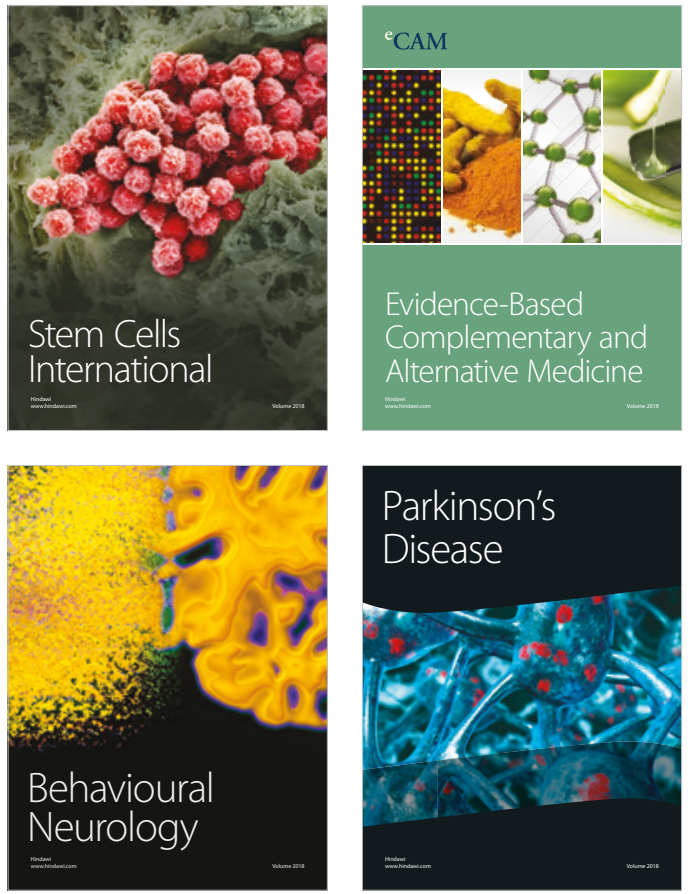

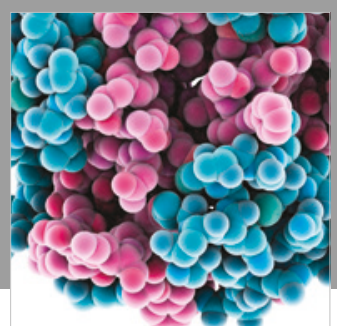

ournal of

Diabetes Research

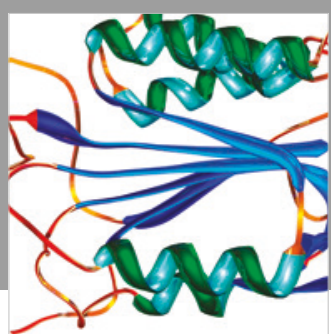

Disease Markers
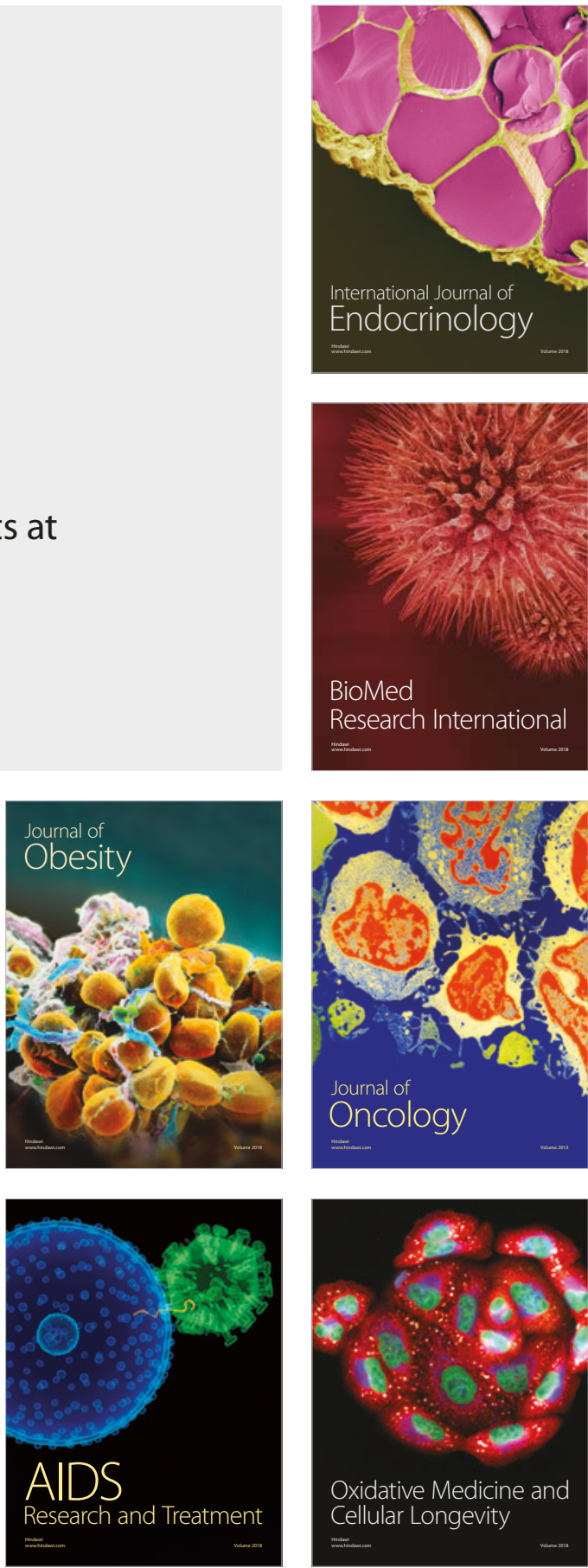